\title{
Metabolic Profiles of Propofol and Fospropofol: Clinical and Forensic Interpretative Aspects
}

\author{
Ricardo Jorge Dinis-Oliveira $\mathbb{D}^{1,2,3}$ \\ ${ }^{1}$ Institute of Research and Advanced Training in Health Sciences and Technologies (IINFACTS), Department of Sciences, \\ University Institute of Health Sciences (IUCS), CESPU, CRL, Gandra, Portugal \\ ${ }^{2}$ UCIBIO-REQUIMTE, Laboratory of Toxicology, Department of Biological Sciences, Faculty of Pharmacy, University of Porto, \\ Porto, Portugal \\ ${ }^{3}$ Department of Public Health, Forensic Sciences, and Medical Education, Faculty of Medicine, University of Porto, Porto, Portugal \\ Correspondence should be addressed to Ricardo Jorge Dinis-Oliveira; ricardinis@med.up.pt
}

Received 22 December 2017; Revised 27 March 2018; Accepted 15 April 2018; Published 24 May 2018

Academic Editor: Hiroshi Tanaka

Copyright (C) 2018 Ricardo Jorge Dinis-Oliveira. This is an open access article distributed under the Creative Commons Attribution License, which permits unrestricted use, distribution, and reproduction in any medium, provided the original work is properly cited.

\begin{abstract}
Propofol is an intravenous short-acting anesthetic widely used to induce and maintain general anesthesia and to provide procedural sedation. The potential for propofol dependency and abuse has been recognized, and several cases of accidental overdose and suicide have emerged, mostly among the health professionals. Different studies have demonstrated an unpredictable interindividual variability of propofol pharmacokinetics and pharmacodynamics with forensic and clinical adverse relevant outcomes (e.g., pronounced respiratory and cardiac depression), namely, due to polymorphisms in the UDP-glucuronosyltransferase and cytochrome P450 isoforms and drugs administered concurrently. In this work the pharmacokinetics of propofol and fospropofol with particular focus on metabolic pathways is fully reviewed. It is concluded that knowing the metabolism of propofol may lead to the development of new clues to help further toxicological and clinical interpretations and to reduce serious adverse reactions such as respiratory failure, metabolic acidosis, rhabdomyolysis, cardiac bradyarrhythmias, hypotension and myocardial failure, anaphylaxis, hypertriglyceridemia, renal failure, hepatomegaly, hepatic steatosis, acute pancreatitis, abuse, and death. Particularly, further studies aiming to characterize polymorphic enzymes involved in the metabolic pathway, the development of additional routine forensic toxicological analysis, and the relatively new field of "omics" technology, namely, metabolomics, can offer more in explaining the unpredictable interindividual variability.
\end{abstract}

\section{Introduction}

A general anesthetic is an unrecognizable chemical drug class that depresses all excitable tissues and produces a reversible state of unconsciousness, with absence of pain sensation over the entire body [1]. The pattern of depression is irregular and descending, with higher cortical functions (i.e., conscious thought, memory, motor control, and perception of sensations) being firstly depressed comparatively to medulla, which contains cardiovascular and respiratory vital centers [1]. In contrast to local anesthetics, the general anesthetics exert their main effects on the central nervous system. It should also be noted that a drug may have useful anesthetic actions without being a good analgesic and vice versa.
Before the development of effective anesthetics and analgesics, as well as blood transfusions and antibiotics, successful major surgery was virtually impossible owing to the severe pain, hemorrhage, and infection; the patient was usually tied, held down, or rendered unconscious by hypoxia, concussion, or high doses of natural central nervous system depressants such as ethanol or opioids [2]. For a drug to be useful as a general anesthetic, its actions must be of rapid onset, effective during the duration of the surgical procedure, then rapidly reversible. Therefore, only those that have short halflives and that can be continually administered are useful, which is not the case of ethanol, benzodiazepines, and the majority of barbiturates [2]. General anesthesia is usually induced by intravenous injection of anesthetic agent (e.g., 
TABLE 1: Systemic therapeutic and adverse or side effects of propofol according to [2, 23-25].

Central Nervous System

(i) Depression with decrease in cerebral blood flow $(\mathrm{CBF})$ and cerebral metabolic rate for oxygen $\left(\mathrm{CMRO}_{2}\right)$ and intracranial pressure (ICP), which may be important in a patient with raised ICP (head trauma, cerebral neoplasia)

(ii) Decrease of intraocular pressure (useful in glaucoma)

(iii) In comparison to thiopental is more or at least equipotent as anticonvulsant in the treatment of epilepsy

(iv) Excitatory phenomena, including muscle twitching and rigidity, paddling and opisthotonus, are occasionally seen at induction. These reactions are believed to be subcortical in origin and are usually transient and proper treatment is rarely required

Respiratory System

(i) Respiratory depression (including apnea) after an induction dose is the most common side effect and may affect the fetus or neonate if used on pregnant women (category C)

(ii) Decrease both respiratory rate and tidal volume, resulting in a rise in arterial partial pressure of carbon dioxide (hypercapnia) and acidosis

(iii) Hypoxia is also possible in the patient breathing room air

(iv) Bronchospasm in patients with reactive airway disease

Cardiovascular System

(i) Greater decrease of blood pressure than other injectable anesthetics due to decreases in myocardial contractility and systemic vascular resistance without a compensatory rise in heart rate. It is thought that it impairs the baroreceptor response to low blood pressure

(ii) Depression that may lead to hypotension and bradycardia due to vasodilatation

(iii) Hypertriglyceridemia ( $>500 \mathrm{mg} / \mathrm{dL}$ ) when infused for greater than 72 hours since lipid emulsion contains $0.1 \mathrm{~g}$ of fat $/ \mathrm{mL}$

(iv) Phlebitis and thrombosis

Skeletal Muscle

(i) Myoclonus is occasionally seen but does not trigger malignant hyperthermia

Miscellaneous Effects

(i) Antimuscarinic or atropine-like syndrome (i.e., agitation, tachycardia, confusion, hallucinations) that can be reversed by physostigmine

(ii) Pancreatitis

(iii) Allergic reactions have not been reported

(iv) Pain on intravenous injection site is common, a fact that can be minimized by using a large vein and by injecting a local anesthetic

(e.g., lidocaine)

(v) No significant endocrine effect, no change in the coagulation profile or platelet count and no significant effect on gastrointestinal motility

(vi) May have antioxidant effects similar to vitamin $\mathrm{E}$

(vii) Decrease nausea and vomiting

(viii) Propofol infusion syndrome

(ix) Pruritus

(x) Benign urine discoloration

(xi) Reduce lymphocyte proliferation and inhibits phagocytosis in vitro

(xii) Abuse

Precautions and Contraindications

(i) Elderly, hypovolemic and hypotensive patients

(ii) Benzodiazepines and other central nervous depressants

ultrashort-acting barbiturates such as thiopental and nonbarbiturates such as propofol, ketamine, and etomidate) and then maintained by inhalation of a gas (e.g., nitrous oxide) mixed with the vapor of a volatile liquids (e.g., desflurane and sevoflurane) and oxygen [3]. Intravenous anesthetic agents are usually defined as drugs that induce loss of consciousness in one arm-brain circulation time (normally 10-20 s), when given in an appropriate dosage.

Propofol (2,6-diisopropylphenol; alkylphenol derivative) was firstly introduced into the market in 1977 by Kay and Rolly $[4,5]$ and is currently the most frequently administered anesthetic drug that largely replaced barbiturates as an induction agent due to its favorable side effects profile, namely, fewer incidences of nausea, vomiting, and postoperative drowsiness [2, 6-8]. Since its pharmacokinetic profile allows for continuous infusions, it is also used for maintenance of general anesthesia (Table 1) either as part of a "balanced anesthesia" regimen in combination with volatile anesthetics, nitrous oxide, sedative-hypnotics, neuromuscular blocking drugs, and opioids or as part of a total intravenous anesthetic technique, usually in combination with opioids. It is also used as hypnotic for patients undergoing mechanical ventilation and for conscious sedation, especially in day-surgery or noninvasive (e.g., radiation therapy, endoscopy, and magnetic resonance imaging) procedures as it causes less nausea and vomiting than do inhalation anesthetics, and it is devoid of 
analgesic properties. The empirical formula of propofol is $\mathrm{C}_{12} \mathrm{H}_{18} \mathrm{O}$, with two isopropyl groups positioned on each side of a hydroxyl group in the ortho-position on a phenol ring.

Several studies have demonstrated an unpredictable interindividual variability of propofol pharmacokinetics and pharmacodynamics with forensic and clinical adverse relevant outcomes (e.g., pronounced respiratory, cardiac depression, and "propofol-related infusion syndrome" (PRIS)), namely, due to polymorphisms in the UDP-glucuronosyltransferase (UGT) and cytochrome P450 (CYP) isoforms and drugs administered concurrently [9-13]. Therefore, due to its narrow therapeutic interval, propofol should be administered only by individuals trained in airway management, and titration of the induction dose helps to prevent severe hemodynamic changes [14]. Moreover, propofol is a final metabolite of other anesthetics such as fospropofol.

The focus of this manuscript is the metabolism and metabolomics of propofol, which is not well characterized in most studies. In the last few years several advances have been made in the knowledge of the specific enzymes isoforms involved in its metabolism, genetic influence, or the pharmacological interactions with other drugs. This work aims to review the preclinical and clinical metabolism and metabolomics of propofol, pharmacologicaland toxicological-related effects in special populations, and analytical considerations. Some important reviews were previously published but metabolism focused only on major metabolic routes and not combined in harmonized and complete pathways. This integrated overview can also be a useful support in evaluating the exact analytical needs and the most suitable techniques and procedures to obtain reliable and complete pharmacokinetic data [15-18].

\section{Methodology}

Aiming to obtain as much as complete integrative review, we carried out an English, German, French, Portuguese, and Spanish exhaustive literature search to identify and analyze relevant articles. Propofol and derivatives and related known metabolizing enzymes and metabolites were searched in books and in PubMed (US National Library of Medicine) without a limiting period. Furthermore, electronic copies of the full papers were obtained from the retrieved journal articles and books on propofol and related compounds (e.g., fospropofol), which were further reviewed for possible additional publications related to human and nonhuman in vivo and in vitro studies.

\section{Propofol Pharmacodynamics}

Compared to other intravenous anesthetics, propofol has a favorable pharmacological profile, namely [7], (i) rapid onset and distribution; (ii) rapid metabolism; (iii) very rapid recovery; (iv) limited cumulative effect that is useful for daycase surgery; (v) being an achiral compound; and (vi) having a low incidence of nausea and vomiting.

The propofol central nervous system depression is probably mediated through $\gamma$-aminobutyric acid (GABA) and glutamatergic N-methyl-D-aspartate (NMDA) receptors, as agonist and antagonist, respectively [30]. Particularly, as a GABAergic anesthetic, propofol modulates the action of GABA at $\mathrm{GABA}_{\mathrm{A}}$ receptors either by prolonging inhibitory postsynaptic currents mediated by $\mathrm{GABA}_{\mathrm{A}}$ receptors or by enhancing GABA release via presynaptic mechanisms [3134]. As widely described, $\mathrm{GABA}_{\mathrm{A}}$ receptors are ligandgated chloride channels made up of five subunits (generally comprising two $\alpha$, two $\beta$, and one $\gamma$ or $\delta$ subunit) [35, 36]. Anesthetics can bind to hydrophobic pockets within different $\mathrm{GABA}_{\mathrm{A}}$ receptor subunits increasing the chloride influx current causing neuronal hyperpolarization. Specific mutations of the amino acid sequence of the $\alpha$ subunit inhibit the actions of volatile anesthetics but not those of intravenous anesthetics, whereas mutations of the $\beta$ subunit inhibit both volatile and intravenous anesthetics $[37,38]$. This suggests that volatile anesthetics may bind at the interface between $\alpha$ and $\beta$ subunits (analogous to benzodiazepines that bind at the interface between $\alpha$ and $\gamma / \delta$ subunits), whereas the intravenous anesthetics may bind only on the $\beta$ subunits. A further level of complexity arises because there are different subtypes of each subunit. Different subunit compositions give rise to subtly different subtypes of $\mathrm{GABA}_{\mathrm{A}}$ receptor and these may be involved in different aspects of anesthetic action.

The $\alpha_{2}$-adrenoreceptor system also seems to play an indirect role in the sedative effects of propofol [39].

\section{Propofol Formulations}

As with other intravenous anesthetic agents, propofol presents an interesting pharmaceutical formulation problem: ideally an IV anesthetic agent must be highly lipid-soluble to cross the blood-brain barrier and act into highly perfused lipid-rich tissues (i.e., brain, spinal cord), yet sufficiently water-soluble to be formulated as a solution that can be safely injected intravenously. Since it is almost insoluble in water at $\mathrm{pH}$ 7.0, propofol is formulated as oil-in-water emulsions (similar to milk) since it forms a $1 \%$ aqueous emulsion with $10 \%$ soyabean oil, $2.25 \%$ glycerol as a tonicity/stabilizing agent, $1.25 \%$ lecithin as emulsifier, the major component of the egg yolk phosphatide fraction, and sodium hydroxide to adjust the $\mathrm{pH}$ [2]. Hence, susceptible patients may experience allergic reactions, but there is no scientific evidence even for those with immunoglobulin E confirmed allergy to egg, soy, or peanut [40]. The resulting formulation is a slightly viscous, milky-white isotonic solution (commonly called the "milk of amnesia" by anesthetists) with a $\mathrm{pH}$ of $7-8.5$ for intravenous injection or infusion. Typically a propofol formulation of $1 \%(10 \mathrm{mg} / \mathrm{mL})$ is available, but in some countries a $2 \%$ concentration is accessible primarily for continuous infusion. Due to oil-in-water emulsion, administration can cause pain on injection [41, 42]. Moreover, since the pharmaceutical formulation is an excellent medium for bacterial growth (e.g., Escherichia coli or Candida albicans), asepsis during administration and storage is necessary [43]. Although retardants of bacterial growth [e.g., ethylenediaminetetraacetic acid $(0.05 \mathrm{mg} / \mathrm{mL})$, metabisulfite $(0.25 \mathrm{mg} / \mathrm{mL})$, or benzyl alcohol $(1 \mathrm{mg} / \mathrm{mL})$ ] are added to the formulations by different 
TABLE 2: Comparison of propofol and fospropofol characteristics according to [14, 26-29].

\begin{tabular}{lcc}
\hline Characteristics & Propofol & Fospropofol \\
\hline Standard dose to induce general anesthesia & $1.5-2.5 \mathrm{mg} / \mathrm{kg}$ (lipid emulsion formulation) & $6.5 \mathrm{mg} / \mathrm{kg}$ (aqueous formulation) \\
Onset of action & $40 \mathrm{~s}-1 \mathrm{~min}$ (“one arm-brain circulation”) & $4-8 \mathrm{~min}$ \\
Duration of action after bolus dose & $3-10 \mathrm{~min}$ & $5-18 \mathrm{~min}$ \\
Volume of distribution (L/kg) & 5.8 & 0.3 \\
Total body clearance (L/h/kg) & 3.2 & 0.36 \\
Terminal phase elimination half-life (h) & 0.97 & 0.88 \\
Protein binding (\%), mostly albumin & $97-99$ & $95-97$ \\
Side effect & Pain on injection and moderate to severe & Transient perineal paresthesia, pruritus and \\
& cardiovascular and respiratory depression & mild cardiovascular and respiratory depression \\
\hline
\end{tabular}

manufactures, it is recommended that the contents of a vial should be discarded within 6 hours after being open. Unopened vials should be stored at $22^{\circ} \mathrm{C}$ and are not light sensitive. The addition of metabisulfite in one of the formulations has raised concern regarding its use in patients with reactive airway disease (e.g., asthma) or sulfite allergies. If storage of propofol is necessary, the vial contents should be aspirated into a sterile syringe, capped with a needle or collected into a plain sterile vacutainer, and used as soon as possible. There are reports of sepsis developing in patients that have been exposed to contaminated propofol $[44,45]$.

\section{Pharmacokinetics of Propofol}

5.1. Absorption. Table 2 presents pharmacokinetic data regarding propofol. Previous reports concluded that propofol itself has little or no oral bioavailability, presumably due to first-pass hepatic metabolism of at least $80 \%$ of an lipid emulsion in animals $[46,47]$ and in humans $[48,49]$. Moreover, propofol is ineffectively given by either intramuscular or subcutaneous routes and therefore it is restricted to intravenous administrations.

5.2. Distribution. After a single bolus or continuous infusion, propofol as other intravenous anesthetics, is best described by a three-compartment linear model $[50,51]$ :

(a) A rapidly equilibrating plasma compartment.

(b) A fast equilibrating compartment (with a distribution half-life of 1-8 minutes) between plasma and highly perfused organs such as the lung, liver, kidneys, and brain. Indeed, due to its high lipid solubility (octanol/water partition coefficient of 4300) [52], propofol easily crosses the blood-brain barrier resulting in a rapid onset (few seconds; also referred to as within one arm-brain circulation time) of anesthesia. The patients are asked to count backwards from 10 as the propofol is injected and they rarely reach 4 or 3 .

(c) A slowly equilibrating deep compartment (with a distribution half-life of 30-70 minutes) between central nervous system and less perfused tissues such as skeletal muscle and adipose tissue. However, this is a rapid redistribution (half-life of 2-4 minutes) that together with a fast metabolism justifies the propofol short duration of effect of only 3-5 minutes and therefore a short recovery period, speed of awakening, and few hangover effects.

Due to its rapid clearance from the central compartment, the slow return of propofol from the deep compartment has little influence on the initial rapid decrease in propofol concentrations. Although the influence of obesity on propofol pharmacokinetics is not entirely clear, the greater the amount of body fat, the briefer the effect of a single IV dose and the greater the distribution volume. Generally, the blood distributes more to nonadipose than to adipose tissues, resulting in higher plasma drug concentrations in obese patients than those patients with less adipose mass. With prolonged administration or large doses, saturation of fat depots leads to prolonged drug action and delayed recovery as drug is slowly released back into the circulation to be eliminated. Consequently, patients administered IV anesthetic agents for short-stay procedures must be advised that they cannot drive or take public transport home and need a responsible person to care for them for 24 hours. Furthermore, propofol clearance increases because of the increased liver volume and liver blood flow associated with obesity (and increased cardiac output).

Propofol is also highly protein-bound (97-99\%), namely, to albumin, and therefore patients with hypoalbuminemia may require a lower dose for anesthesia induction [53-57]. It is also possible that propofol competes with other drugs for the same albumin binding site. To prolong anesthesia, small boluses can be given as required or alternatively an infusion can be administered. Propofol also tightly binds to erythrocytes [58].

5.3. Metabolism of Propofol. Although most volatile anesthetics are excreted unchanged by the lungs, with less than $5 \%$ being metabolized by CYP enzymes primarily CYP2E1, intravenous anesthetics undergo extensive metabolism by the CYP enzymes or UGT prior to excretion in the kidney. The rate of metabolism varies with species, age, the physical condition of the animal, and the presence or absence of concurrently administered drugs [59].

Propofol undergoes rapid and extensive metabolism to water-soluble inactive metabolites. The liver is the major 


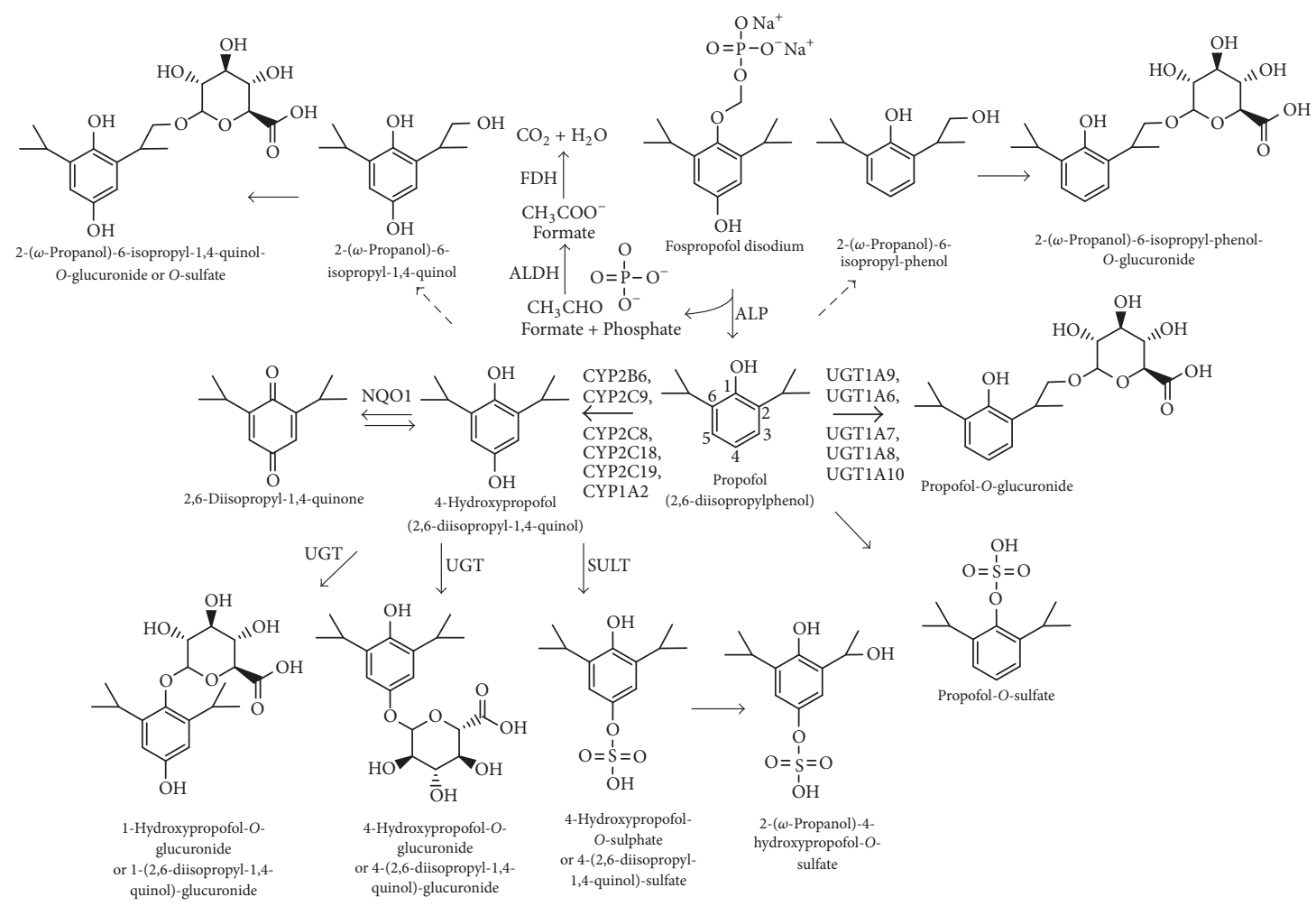

Figure 1: Metabolic pathway of propofol and fospropofol. Dashed arrows represent minor routes and both metabolites can undergo glucuronide and sulfate conjugation. SULT: sulfotransferase; UGT: UDP-glucuronosyltransferase; ALDH: aldehyde dehydrogenase; ALP: alkaline phosphatase; NQO1: diaphorase; CYP: cytochrome P450.

metabolic site, but extrahepatic clearance of propofol has also been suggested since systemic propofol clearance exceeds hepatic blood flow $[60,61]$. Indeed, in patients undergoing liver transplantation, the amount of propofol metabolite excretion did not decrease during the anhepatic phases when the liver was excluded from the circulation [62-65]. The lungs are responsible for approximately $30 \%$ of the uptake and firstpass elimination after a bolus dose [66]. During a continuous infusion of propofol, there is a $20 \%$ to $30 \%$ decrease of the propofol concentration measured across the lung in humans and a higher concentration of the metabolite 2,6-diisopropyl1,4-quinol on the arterial side of the circulation [67]. The human brain, kidney, and small intestine are also important organs for extrahepatic metabolism of propofol [61].

Metabolic pathways of propofol were studied in several species and include direct conjugation of the hydroxyl group and $p$-position aromatic or aliphatic hydroxylation followed by conjugation of 2,6-diisopropyl-1,4-quinol with glucuronic acid at $\mathrm{C} 1$ and $\mathrm{C} 4$ positions and sulfate at $\mathrm{C} 4$ position (Figure 1) [57, 60, 68, 69]. 2,6-Diisopropyl-1,4-quinol may undergo chemical or by-diaphorase $(\mathrm{NAD}(\mathrm{P}) \mathrm{H}$ dehydrogenase [quinone] 1; NQO1) conversion in 1,4-quinone by tautomeric equilibrium [70]. All metabolites are inactive, except 2,6-diisopropyl-1,4-quinol which has about one-third the hypnotic activity of propofol [71].

UGTs are phase II drug metabolizing enzymes that catalyze the glucuronidation of a wide variety of endobiotics and xenobiotics [9]. Propofol is primarily and extensively
( $40 \%$ in humans) metabolized in liver, only through glucuronidation to propofol-glucuronide by enzymes coded by the UGT1A9 gene located on chromosome 2q37 [72] . UGT1A9 also conjugates other phenols, estrogen and thyroid hormones, acetaminophen, and SN-38 (an active metabolite of irinotecan) $[73,74]$. The other main metabolites are the 1glucuronide and the 4-glucuronide of the 1,4-quinol which account each for roughly $20 \%$ of the total propofol metabolites $[75,76]$. UGT1A9 is primarily expressed in the liver but also in extrahepatic tissues such as kidney, small intestine, colon, and reproductive organs such as the testis and ovary $[77,78]$. Variations in this gene significantly affect propofol metabolism; homozygous UGT1A9 726G/G variant has been associated with a loss of UGT1A9 activity [72], whereas the UGT1A D256N variant decreases propofol glucuronidation [9]. Authors suggested that carriers of D256N may be at risk of suffering adverse effects of propofol and other substrates that are primarily metabolized by UGT1A9 [9]. Mehlotra et al. found D256N with allele frequency 0.005 in AsianAmericans [79]. In a pilot study, Loryan et al. [10] found no association between the observed sex differences in propofol glucuronidation and UGT1A9 expression. The results were confirmed in a replication study [80]. However, patients who are heterozygous with UGT1A9-1887T/G variant required a statistically significant higher induction dose of propofol compared to those with other variants [81]. In addition, UGT1A9-133T/C was associated with higher propofol clearance (heterozygous with higher clearance than the rest). 
This study found no significant relationship between clinical differences and CYP2B6, GABRE, or other variants of the UGT1A9 gene [81]. A study of 150 Caucasian patients did not find any significant relationship between the four major haplotypes (set of DNA variants or polymorphisms that are inherited together) of the GABRE gene (that codes the GABA receptor, mRNA358G/T, 20118C/T, 20502A/T, and 20326C/T) and induction time with propofol [82].

The UGT1A6 has also been suggested to contribute to the hepatic and extrahepatic propofol metabolism [61, 83]. Although UGT1A9 is the main enzyme involved in the glucuronidation of propofol in humans, it does not exists in rats $[84,85]$. However, UGT1A6 enzyme is detected in various tissues in rats and humans and has a similar homology as UGT1A9 [85, 86]. The UGT1A8, expressed mainly in the digestive organs but not in the liver, has also been shown to conjugate propofol $[87,88]$. UGT1A7 and UGT1A10 also conjugate propofol in extrahepatic organs such as the kidneys and intestine [89].

In vivo studies previously identified marked species differences in the pharmacokinetic and metabolic profiles of propofol among rats, rabbits, and dogs [57, 68, 69], and these differences have been attributed to the levels of expression and function of the UGT isoform(s) responsible for propofol glucuronidation in each animal species and are sex-dependent [90].

Although with much less extent than glucuronidation, sulfation of propofol catalyzed by sulfotransferase (SULT) has also been described as minor metabolite involved in propofol clearance in humans $[68,91]$. While the 1-OH group of propofol is sterically hindered by the two isopropyl groups and therefore coupling with the small $\mathrm{SO}_{4}{ }^{-}$group would be much more likely than the addition of glucuronic acid, several studies demonstrated significantly higher concentrations of propofol-glucuronide compared to propofol sulfate [92, 93].

Regarding phase I metabolism, the propofol hydroxylation by CYP represents a minor metabolic route. Nevertheless, this route could be basis of metabolic interactions or relevant genetic polymorphisms [94]. Aromatic hydroxylation is partially mediated by CYP2C9 $(\sim 50 \%)$ or CYP2B6 in human liver, especially at low substrate concentration $[95,96]$. Moreover, propofol was likely to be metabolized by additional isoforms such as CYP2A6, CYP2C8, CYP2C18, CYP2C19, and CYP1A2, especially when substrate concentrations are high [95]. From a clinical perspective, this low specificity among CYP isoforms may contribute to a low interindividual variability and reduced metabolic drug interactions [95], but opposite results have been observed [97]. Indeed, in spite of its low $(1-5 \%)$ contribution to the total liver CYP content, CYP2B6 polymorphisms also have a significant impact on the CYP2B6-dependent metabolism of several clinically relevant drugs such as cyclophosphamide, $S$-methadone, efavirenz, nevirapine, bupropion, selegiline, and propofol [98, 99]. Propofol is predominantly $p$-hydroxylated by CYP2B6 into hydroxyl propofol [100]. The gene for CYP2B6 has become noteworthy as one of the most polymorphic CYP genes, with a 20- to 250-fold variation in interindividual CYP2B6 expression. CYP2B6 genetic variation is responsible for the interindividual variability in propofol metabolism $[9,82,101]$.
Indeed, the occurrence of the CYP2B $6 * 6$ allele has been associated with decreased enzyme activity compared to the wild type $(\mathrm{CYP} 2 \mathrm{~B} 6 * 1)$. Kansaku et al. [11] reported a high plasma concentration of propofol in individuals with CYP2B6 c.516G>T, a marker of the CYP2B $6 * 6$ allele that correlated with awakening time and risk index score. The adverse reactions risk index score included age of $>65$ years and simultaneous occurrence of CYP2B6 cG516T and UGT1A9 1366C>T [11]. Thus, elderly patients with CYP2B6 c.G516T and UGT1A9 C1366T may be at a higher risk of propofol-related adverse events, such as PRIS and cardiovascular instability. In addition, of clinical relevance, women (particularly Hispanic-American women) express considerably higher hepatic levels of CYP2B6 protein than men. On average, women require high doses for induction, produce more metabolites, and recover more quickly than men during a propofol anesthetic $[10,80]$, which may lead to female subjects being at an increased risk of awareness during propofol anesthesia. Using a more sensitive measure of propofol concentration, Mastrogianni et al. [102] reported that women with the $\mathrm{T}$ allele in the CYP2B6 c.516G $>\mathrm{T}$ had a statistically significant higher plasma concentration of propofol than noncarriers. Other attempts to link CYP2B6 and propofol requirements of metabolism yielded no statistically significant results. Regarding the c.1075A $>$ C polymorphism in the CYP2C9 genes did not affect the pharmacokinetic profile of propofol among Polish patients [97].

Introduction of a hydroxyl group on the isopropyl group (2-( $\omega$-propanol)-6-isopropyl-phenol $=2-\omega$-phenol $)$ and in both positions (2-( $\omega$-propanol)-6-isopropyl-1,4-quinol $=2$ $\omega$-quinol) and glucuronidation and sulfation of these moieties was also described [103].

Previous investigations have shown that propofol decreased animal [104] or human [94] CYP activities in vitro, perhaps by interacting with the haem moiety. Indeed, propofol itself results in a concentration-dependent inhibition of CYP3A4 and may alter the metabolism of drugs dependent on this enzyme such as opioids [105]. Moreover, since propofol reduces hepatic blood flow, the clearance of other drugs metabolized in the liver may be reduced [106]. Propofol is also known for modulating UGT1A1 activity for 4-methylumbelliferone and estradiol 3 - $\beta$-glucuronidation [107].

5.4. Elimination. Propofol is mainly eliminated (73\% of the dose in $24 \mathrm{~h}$ and $88 \%$ in $120 \mathrm{~h}$ ) by glomerular filtration (renal clearance of $120 \mathrm{ml} / \mathrm{min}$ ) as water-soluble metabolites and/or bile $[108,109]$. Less than $1 \%$ of propofol is excreted unchanged in urine, and clearance is reduced in renal failure; only $2 \%$ is excreted in feces up to $48 \mathrm{~h}$ after dose $[109,110]$. In humans, the major metabolite in urine is the glucuronic acid conjugate of propofol, which accounts for $53-73 \%$ of the total metabolites, depending mainly on the administered dose of propofol [111]. Enterohepatic circulation of propofolglucuronide was demonstrated in rat and to a lesser extent in $\mathrm{dog}$ and absent in rabbit [71]. Glucuronic acid conjugates at the $\mathrm{C} 1$ or $\mathrm{C} 4$ positions and the sulfate conjugates at the $\mathrm{C} 4$ position of 2,6-diisopropyl-1,4-quinol (the ring-hydroxylated derivative of propofol) are the other metabolites recovered 
in human urine [111]. The long terminal elimination half-life of 4-23 hours indicates a deep compartment with limited perfusion, which results in a slow return of propofol back to the central compartment $[2,112]$. Plasma clearance is high $(20-30 \mathrm{mg} / \mathrm{kg} / \mathrm{min})$ and exceeds hepatic blood flow, indicating the importance of extrahepatic metabolism [62, 113]. Although most of a single dose of propofol is excreted within 24 hours, excretion from deep tissues into the urine may take up to six days with minor metabolites resulting from hydroxylation on the isopropyl side chain being recovered $[75,103]$.

\section{Fospropofol: A Prodrug of Propofol}

Fospropofol (2,6-diisopropylphenoxymethyl phosphate disodium salt) is a recently developed water-soluble derivative that, in comparison to propofol lipid emulsion, is less painful on injection and has lower risk of bacterial contamination and hypertriglyceridemia [7]. It was licensed in 2008 by the Food and Drug Administration (FDA) and is formulated as a clear to slightly yellow aqueous solution containing $3.5 \%$ of fospropofol, monothioglycerol $(0.25 \% \mathrm{w} / \mathrm{v})$, and tromethamine $(0.12 \% \mathrm{w} / \mathrm{v})$. The $\mathrm{pH}$ of the solution is $8.2-9.0$. It is a phosphono-O-methyl prodrug that has a methyl phosphate group substituted at the $\mathrm{C} 1$ hydroxyl group of the propofol molecule that is rapidly converted by endothelial cell surface alkaline phosphatases to propofol (the active metabolite), phosphate, and formaldehyde [114]. The formaldehyde is then metabolized by aldehyde dehydrogenase (ALDH) in the liver and in erythrocytes to formate, which is then safely metabolized by 10 -formyltetrahydrofolate dehydrogenase to $\mathrm{CO}_{2}$ and $\mathrm{H}_{2} \mathrm{O}$ with tetrahydrofolate as coenzyme, similarly to the other available phosphate methyl prodrugs such as fosphenytoin $[115,116]$. Clinical studies did not note serum toxic formaldehyde concentrations, which may ultimately lead to metabolic acidosis, loss of vision, and death [117, 118]. Indeed, physiological or fospropofol infusion-related formate concentrations have been measured in the range of $13 \pm$ $7 \mu \mathrm{g} / \mathrm{mL}$ [119], while formate concentrations in patients who died of methanol intoxication were reported to be at least 350 times higher in the range of $7-11 \mathrm{mg} / \mathrm{mL}$ [120].

The available fospropofol formulation is a sterile, aqueous, colorless, and clear solution that is supplied in a single dose vial at a concentration of $35 \mathrm{mg} / \mathrm{mL}$ [2]. Since it is a prodrug, pharmacokinetics is more complex (Table 2) than for propofol itself. Fospropofol follows a two-compartment model while as mentioned previously a three-compartment model has been used to describe the kinetics of propofol [115]. The pharmacodynamics profile is similar to that of propofol, but fospropofol disodium has a higher onset of action and recovery is prolonged since the prodrug must first be converted into an active metabolite. Although patients receiving fospropofol do not appear to experience the injection pain typical of propofol, a common adverse effect is the experience of paresthesia, often in the perianal region, which occurs in up to $74 \%$ of patients. The mechanism for this effect is unknown. Fospropofol is currently approved for sedation during monitored anesthesia care.
Interestingly, oral administration of the fospropofol provides appreciable propofol bioavailability in both animal and human volunteers in comparison to the negligible oral bioavailability of propofol [121]. While propofol availability derived from the prodrug is appreciable, the bioavailability of the prodrug itself is low, suggesting that propofol is liberated from prodrug before entering the central compartment [121]. Most common adverse events include paresthesia and pruritus, probably caused by the phosphate ester component released and less serious hypoxemia and hypotension than propofol [26]. Since the molecular weight of propofol is $178.27 \mathrm{~g} / \mathrm{mol}$ and the molecular weight of fospropofol is 332.24 , both drugs are not equipotent, with $1.86 \mathrm{mg}$ of propofol disodium being molar equivalent to $1 \mathrm{mg}$ of propofol [122]. Serum toxic phosphate levels are not reached due to an efficient kidney elimination. Renal elimination of fospropofol is negligible $(<0.02 \%)$ [27].

\section{Propofol Metabolism and Related Urine Discoloration}

Urine discoloration due to propofol infusion is a benign, nonnephrotoxic side effect that has been previously described several times in the literature; majority of cases are related to continuous and prolonged anesthesia and rarely seen in patients during induction of anesthesia or for sedation [123128]. Case reports describe green, pink, white, brown, and red-brown urine associated with propofol use (Figure 2) $[20,129,130]$. Green discoloration represents majority of reported cases, but other compounds (both xenobiotics and endobiotics) such as biliverdin (in cases of long standing obstructive jaundice), amitriptyline, indomethacin, cimetidine, metoclopramide, methocarbamol, osmotic therapy and promethazine, methylene blue (bluish green), food coloring and indigo dyes, and urinary tract infection by Pseudomonas aeruginosa have also been implicated [131-136]. Since it is a nonharmful situation per se, neither healthcare staff nor relatives should be alarmed. The green urine usually resolved after propofol discontinuation in a matter of hours [137]. If urine analysis is normal, the accountable drug should be identified by pausing medications that are known for this side effect. The mechanism of propofol-induced urine green discoloration is unknown, but several causes have been proposed:

(a) Blakey and Hixson-Wallace [128] reported that the green discoloration of the urine due to propofol is attributable to the presence of phenolic chromophores resulting in hepatic metabolites of propofol, such as 1-glucuronide, 4-glucuronide, and 4sulfate conjugates of 2,6-diisopropyl-1,4-quinol [109]. Although they are of no clinical significance, they do serve as an indicator of relative urine $\mathrm{pH}$ where alkalinization increases and acidification decreases formation of these phenolic derivatives [109]. Urinary discoloration can worsen at the time of alcohol consumption due to the augmented activity of CYP- and UGT-related clearance of propofol leading to higher concentration of its metabolites [138]. 


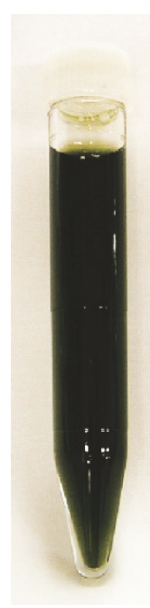

(a)

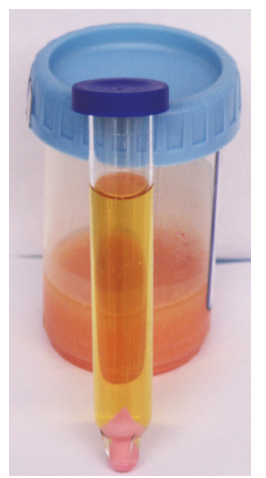

(d)

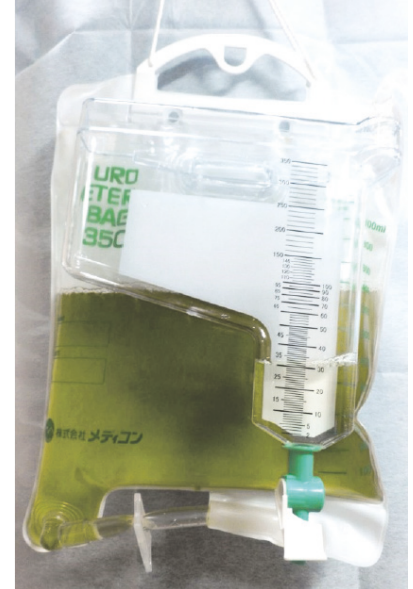

(b)

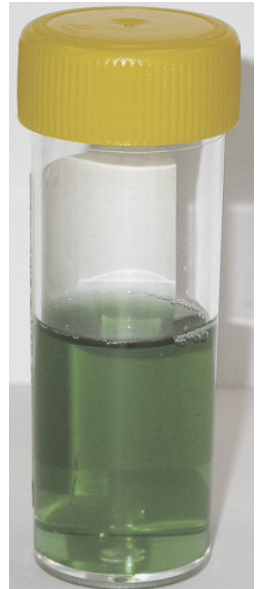

(c)

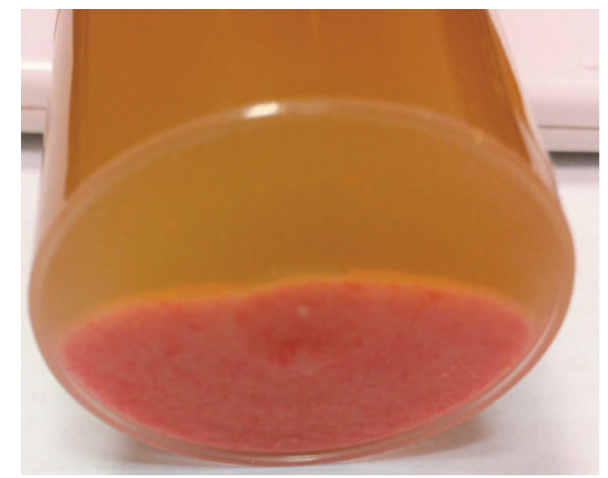

(e)

FIGURE 2: Green and pink urine discoloration after propofol infusion. Pink urine deposits/pellets were obtained after centrifugation. Reproduced with permission from (a) [19], (b) [20], (c) [21], (d) [20], and (e) [22].

(b) Pedersen et al. [137] also reported that the discoloration appears when the clearance of propofol exceeds hepatic elimination and extrahepatic elimination of propofol occurs [139].

(c) Shioya et al. [19] reported that green urine was associated with enterohepatic circulatory failure due to constipation and impaired peristalsis, supplement of albumin and erythrocytes as carrier proteins due to administration of an albumin preparation and concentrated red cells, and extrahepatic glucuronidation in the kidneys.

(d) Fujii-Abe et al. [140] by performing liquid chromatography-mass spectrometry (LC-MS) registered 2 unique peaks in the green urine at 490 and $590 \mathrm{~nm}$, with the complementary colors being orange and blue, respectively. It was assumed that green urine was observed because of a mixture of these 2 colors. Whereas the mass chromatographic peak corresponding to $490 \mathrm{~nm}$ was assumed to be L-urobilin, which is a common metabolite in normal urine, the peak corresponding to $590 \mathrm{~nm}$ was not identified. Moreover, the chromatographic peaks of the inactive metabolites 1-(2,6-diisopropyl-1,4-quinol)-glucuronide and 4-(2,6-diisopropyl-1,4-quinol)-sulfate were not observed in the urine samples, meaning that the real cause for urine discoloration remains unknown.

Besides urine, hair and liver green discoloration after propofol administration was also claimed to be due to phenol metabolites [141, 142]. Why this phenomenon is not observed in all propofol-treated patients is not known, but may, be partially related to prolonged administration. It is also widely reported that propofol is associated with transient pink urine discoloration possibly related to precipitation of amorphous uric acid crystals when urine osmolarity increases and $\mathrm{pH}$ is low $[20,22,129,143,144]$. Indeed, pure uric acid dihydrate crystals are colorless but can become pink when they absorb urinary pigments. The mechanism of pink urine remains unclear. It has been postulated that stress-related secretions of antidiuretics hormones increase the renal clearance of uric acid and cause uric acid crystalluria, which turns urine pink [145-147]. Indeed, obesity, especially with metabolic syndrome, may impair alkalinization of urine and thereby lead to the precipitation of uric acid. Moreover, surgery can stimulate antidiuretic hormone secretion. Stimulation of the V1 receptor can lead to impaired tubular resorption of uric acid, resulting in uric aciduria [20]. Pink urine is an unusual occurrence that has been described using some laxatives 
(phenolphthalein) or antipsychotics, such as chlorpromazine and thioridazine [148]. Full recovery without complications can be expected. Nevertheless, the risk of uric acid lithiasis should be borne in mind.

White urine discoloration was occasionally related to vehicle of the propofol emulsion [130].

\section{Metabolomics of Propofol}

The metabolomics of propofol was not yet extensively studied with only four publications reported in Medline. This is a relatively new field of "omics" technology that is primarily concerned with the "global" quantitative and qualitative biochemical characterization of small molecules (i.e., the metabolome) at specific time points, produced by the genome of the host organism and by the genomes of its microflora or deriving from food, drinks, pollutants, and drugs and their metabolites $[15,149]$. It was recently evidenced that different anesthetics (i.e., propofol and etomidate) but at equipotent dose ranges induced small but meaningful differences in the plasma metabolic profiles by proton magnetic resonance spectroscopy ( ${ }^{1}$ HNMR) [150]. Moreover, Jacob et al. [151] found higher glucose and lactate levels with sevoflurane in the human brain compared with propofol. They suggest that findings could reflect greater neuronal activity with sevoflurane resulting in enhanced glutamate-neurotransmitter cycling, increased glycolysis, and lactate shuttling from astrocytes to neurons or mitochondrial dysfunction [151, 152]. Corroborating results, Alkire et al. [153] assessed cerebral glucose metabolism in volunteers by positron emission tomography (PET) before and during infusion of propofol to the point of unresponsiveness. The whole-brain metabolic rate decreased by $48 \%$ to $58 \%$, with limited regional heterogeneity observed.

\section{Propofol Abuse}

Propofol abuse was firstly described in 1992 [154, 155] but only gained considerable attention in recent years mostly due to fatal prescription cases by celebrities (e.g., Heath Ledger and Michael Jackson) and by healthcare professionals [156, 157]. Indeed, since propofol has prescription status and is generally only distributed to anesthesiologist or physician's offices which commonly perform out-patient surgeries, it predisposes the healthcare specialist population to abuse [3]. Therefore, propofol is most commonly abused by nurses and physicians, especially those working frequently with anesthetics, but has recently also spread to wider populations as well $[158,159]$. The abuse potential of propofol is generally regarded as low, namely, due to the short duration of action. Nevertheless, the fast onset of creating a short ecstatic and euphoric feeling, the capacity to induce sexual delusions, fantasies, and disinhibition, without many of the side effects that are associated with other drugs, and the fact of not being a controlled substance are the main reasons for its widespread abuse $[158,160]$. Pharmacodynamically, propofol increases dopamine concentrations in the nucleus accumbens, a phenomenon noted with other addictive psychoactive substances [161-164]. Chronic propofol abuse can result in tolerance, and repeated injections exceeding 100 times per day have been reported $[163,165]$. No physical dependence has been described by abusers and there are only scarce reports on possible withdrawal phenomena after the use of propofol for medical purposes $[166,167]$.

\section{Adverse Effects, Fatal Intoxications, and Autopsy Findings}

Table 1 presents major adverse and side effects of propofol. The pronounced respiratory and cardiac depression are relevant adverse outcomes. There have been also reports of a PRIS occurring in approximately 1 in 300 patients when it has been given in high doses and for a prolonged period to maintain sedation, particularly critically ill patients in intensive care units and children [168, 169]. PRIS is characterized by severe metabolic acidosis, skeletal muscle necrosis (rhabdomyolysis), hyperkaliemia, lipaemia, hepatomegaly, renal failure, arrhythmia and cardiovascular failure, and death. The pathophysiology of PRIS appears to involve a disturbance of mitochondrial metabolism by affecting $\beta$-oxidation of free fatty acids $[168,170,171]$.

The risk of death due to self-administered propofol has been debated and several authors reported it to be low or absent, namely, due to the low concentration found in commercial ampoules ( $20 \mathrm{ml}$ contains $200 \mathrm{mg}$ propofol) that is equivalent to a standard dose of $2-2.5 \mathrm{mg} / \mathrm{kg}$ body weight to a healthy $80 \mathrm{~kg}$ individual to induce general anesthesia within 1-2 min after injection and arousal after 5-10 $\min [159,172$, 173]. Due to the fast-acting narcotic effect of propofol, the self-injection of more than one ampoule at a time is unlikely. However, victim can mix the content of one or more vials for rapid and continuous intravenous infusion and therefore administration will continue despite loss of consciousness [3]. Another challenge that faces forensic toxicologists is the fact that in most case reports of fatal propofol abuse, blood concentrations were lower or within the commonly accepted therapeutic range $(1-8 \mu \mathrm{g} / \mathrm{mL})$ after a standard anesthetic induction dose $[158,159,173,174]$. According to the short half-life, this may suggest that after losing consciousness, the victim probably survived enough time to reduce blood propofol level through distribution, metabolism, and excretion [175]. Nevertheless, for results interpretation it is important to remember that therapeutic levels of propofol apply to an anesthetized patient with respiratory support which is lacking in reported propofol abuse cases and that there is a wide variability of propofol plasma concentrations [173]. Moreover, propofol is also coabused with other drugs, namely, benzodiazepines, z-drugs, barbiturates, and opioids [158]. Indeed, a synergistic interaction has been found with benzodiazepines at the $\mathrm{GABA}_{\mathrm{A}}$ receptors, such that the dose of propofol required to induce anesthesia should be reduced in the presence of midazolam [176].

One of the major drawbacks for the diagnosis of propofol forensic intoxications is the fact it is usually not included in standard drug screening analysis and, due to its low molecular weight and volatility, might be missed even in confirmatory exams. Although newer techniques are available for the 
direct detection of minute quantities of propofol in exhaled air of anesthetized patients [177], such approaches are not readily available in forensic institutions and therefore there is also a long field of opportunities to uncover abusive cases.

Autopsy and histological findings observed in lethal cases resulting from propofol overdose usually report cerebral and pulmonary edema, polyvisceral congestion, lungs with some petechial hemorrhages on pleural surface, hemorrhagic pancreatitis, and hepatic steatosis $[158,160,178]$. Although claimed as very rare idiosyncratic reaction $(<1 / 10,000)$ and with a an estimated incidence of $0.1 \%-2 \%$ of all pancreatitis cases, hypertriglyceridaemia has been suggested as a causal relationship between propofol and pancreatitis since it is formulated as a fat emulsion [179]. Therefore, patients who develop hypertriglyceridaemia are at risk of developing pancreatitis, and serum triglyceride concentrations should be routinely monitored in these patients and alternative sedation strategies should be considered when hypertriglyceridemia is detected $[178,179]$. Nevertheless, some case reports describe the development of propofol-induced acute pancreatitis in the absence of hypertriglyceridaemia [180].

\section{Conclusion and Future Perspectives}

Drugs with actions on the central nervous system are of particular importance in pharmacology, and major groups include anxiolytics, sedatives and hypnotics, antiepileptic, antipsychotics, antidepressant, antiparkinson, stimulants, general anesthetics, opioids, drugs for preventing or treating migraine, and miscellaneous drugs, including anticholinesterases, appetite suppressants, and centrally acting muscle relaxants. Other drugs may be administered to prevent or treat general pathologies to brain tissue (e.g., cytotoxic agents for tumors, antibiotics for infections, or antiinflammatory agents in cerebral edema). Additionally, many drugs given for peripheral effects may cross the blood-brain barrier and have side effects on the central nervous system (e.g., autonomic drugs, antihistamines, and local anesthetics) and psychoactive illicit substances also exert central nervous system actions.

In this work, metabolism of propofol and respective genetic variability was fully reviewed. In humans, propofol produces inactive metabolites. It undergoes direct polymorphic $O$-glucuronidation in humans to propofol-glucuronide and hydroxylation to 2,6-diisopropyl-1,4-quinol. The latter substance subsequently undergoes phase II metabolism, resulting in the formation of further metabolites 4-(2,6diisopropyl-1,4-quinol)-sulfate, 1- and 4-(2,6-diisopropyl1,4)-glucuronides, or sulfates [103]. Further minor phase I propofol metabolites such as 2-( $\omega$-propanol)-6-isopropylphenol and 2-( $\omega$-propanol)-6-isopropyl-1,4-quinol are also described. Propofol is excreted in the urine after glucuroconjugation of the parent drug (to form the propofolglucuronide) and sulfo- and glucuroconjugation of the hydroxylated metabolite to form 4-(2,6-diisopropyl-1,4quinol)-sulfate, 1- or 4-(2,6-diisopropyl-1,4)-glucuronide, respectively. Current evidence suggests that close monitoring is required when administering anesthetics to individuals with the CYP2B6*6 allele [181]. Nevertheless, additional studies are needed to elucidate and characterize polymorphic enzymes in explaining interindividual variations of the glucuronidation metabolic pathway and their pharmacological and toxicological adverse reactions. Although positive pharmacogenetic polymorphic associations have been found with clinical significance, the lack of reproducibility is a limitation, since most studies focus on single variant associations, while interindividual differences in propofol metabolism may be best explained through the contribution of multiple pathways. Indeed, the narrow therapeutic index and significant variability in patients' responses to anesthesia and surgery make the potential for severe adverse reactions high during the perioperative period. The identification of additional metabolites is also required to confirm xenobiotic exposure in a wider detection window, especially in alternative samples. Moreover, despite the fact that there are sex and racial/ethnic differences in response to propofol, to date, there is no strong evidence linking genetic variation to such observations, possibly due to the additional influence of weight, height, and lean body mass, environmental factors, and severe hepatic or renal impairment propofol pharmacokinetics [182-185]. Equally important is the potential for variation at the site of propofol action. In vitro it was shown that $\mathrm{Y} 444 \mathrm{~W}$ variant attenuates the effect of propofol, but associations with $\mathrm{GABA}_{\mathrm{A}}$ receptor polymorphisms and clinical relevant effects of propofol need further studies [186]. Sites on the $\beta_{1}$-subunit (M 286), $\beta_{2}$-subunit (M 286), and $\beta_{3}$-subunit (N265) of the transmembrane domains are crucial for the hypnotic action of propofol $[187,188]$. The $\alpha$-subunit and $\gamma_{2}$-subunit subtypes also seem to contribute to modulating the effects of propofol on the GABA receptor [189].

Finally, metabolomics of propofol was not yet extensively studied and further studies are needed to clarify whether the different metabolomic patterns are significant from the clinical point of view, namely, taking into account sex, age, genetic polymorphisms, and different pathologic conditions.

\section{Conflicts of Interest}

The author has no relevant affiliations or financial involvement with any organization or entity with a financial interest in or financial conflict with the subject matter or materials discussed in the manuscript. This includes employment, consultancies, honoraria, stock ownership or options, expert testimony, grants or patents received or pending, or royalties.

\section{Acknowledgments}

The author acknowledges Fundação para a Ciência e a Tecnologia (FCT) for his Investigator Grant (IF/01147/2013). This work was supported by FEDER under Program PT2020 (Project 007265 -UID/QUI/50006/2013).

\section{References}

[1] A. R. Aitkenhead, I. K. Moppett, and J. P. Thompson, Smith and Aitkenhead's Textbook of Anaesthesia, Churchill Livingstone, Edinburgh, Scotland, 6th edition, 2013. 
[2] M. C. Pardo and R. D. Miller, Basics of Anesthesia, Elsevier, Pennsylvania, Pa, USA, 7th edition, 2018.

[3] A. P. Colucci, R. Gagliano-Candela, L. Aventaggiato et al., "Suicide by self-administration of a drug mixture (propofol, midazolam, and zolpidem) in an anesthesiologist: the first case report in Italy," Journal of Forensic Sciences, vol. 58, no. 3, pp. 837-841, 2013.

[4] B. Kay and G. Rolly, "I.C.I. 35868 - The effect of a change of formulation on the incidence of pain after intravenous injection," Acta Anaesthesiologica Belgica, vol. 28, no. 4, pp. 317322, 1977.

[5] B. Kay and G. Rolly, "I.C.I. 35868, a new intravenous induction agent," Acta Anaesthesiologica Belgica, vol. 28, no. 4, pp. 303-316, 1977.

[6] A. Hartle and S. Malhotra, "The safety of propofol," BMJ, vol. 339, no. 7727, p. 928, 2009.

[7] A. Y. Feng, A. D. Kaye, R. J. Kaye, K. Belani, and R. D. Urman, "Novel propofol derivatives and implications for anesthesia practice," Journal of Anaesthesiology Clinical Pharmacology, vol. 33, no. 1, pp. 9-15, 2017.

[8] G. C. Cummings, J. Dixon, N. H. Kay et al., "Dose requirements of ICI 35,868 (propofol, 'Diprivan') in a new formulation for induction of anaesthesia," Anaesthesia, vol. 39, no. 12, pp. 11681171, 1984.

[9] H. Takahashi, Y. Maruo, A. Mori, M. Iwai, H. Sato, and Y. Takeuchi, "Effect of D256N and Y483D on propofol glucuronidation by human uridine 5/-diphosphate glucuronosyltransferase (UGT1A9)," Basic \& Clinical Pharmacology \& Toxicology, vol. 103, no. 2, pp. 131-136, 2008.

[10] I. Loryan, M. Lindqvist, I. Johansson et al., "Influence of sex on propofol metabolism, a pilot study: implications for propofol anesthesia," European Journal of Clinical Pharmacology, vol. 68, no. 4, pp. 397-406, 2012.

[11] F. Kansaku, T. Kumai, K. Sasaki et al., "Individual differences in pharmacokinetics and pharmacodynamics of anesthetic agent propofol with regard to CYP2B6 and UGT1A9 genotype and patient age," Drug Metabolism and Pharmacokinetics, vol. 26, no. 5, pp. 532-537, 2011.

[12] M. R. Tramer, R. A. Moore, and H. J. Mcquay, "Propofol and bradycardia: causation, frequency and severity," British Journal of Anaesthesia, vol. 78, no. 6, pp. 642-651, 1997.

[13] J. W. Dundee, F. P. Robinson, J. S. C. McCollum, and C. C. Patterson, "Sensitivity to propofol in the elderly," Anaesthesia, vol. 41, no. 5, pp. 482-485, 1986.

[14] B. G. Katzung and A. J. Trevor, Eds., Basic and Clinical Pharmacology, McGraw-Hill, New York, NY, USA, 13 edition, 2015.

[15] R. J. Dinis-Oliveira, "Metabolomics of drugs of abuse: a more realistic view of the toxicological complexity," Bioanalysis, vol. 6, no. 23, pp. 3155-3159, 2014.

[16] R. J. Dinis-Oliveira, "Metabolomics of cocaine: implications in toxicity," Toxicology Mechanisms and Methods, vol. 25, no. 6, pp. 494-500, 2015.

[17] R. J. Dinis-Oliveira, "Oxidative and non-oxidative metabolomics of ethanol," Current Drug Metabolism, vol. 17, no. 4, pp. 327-335, 2016.

[18] R. J. Dinis-Oliveira, "Metabolomics of $\delta 9$-tetrahydrocannabinol: implications in toxicity," Drug Metabolism Reviews, vol. 48, no. 1, pp. 80-87, 2016.

[19] N. Shioya, Y. Ishibe, S. Shibata et al., "Green urine discoloration due to propofol infusion: a case report," Case Reports in Emergency Medicine, vol. 2011, Article ID 242514, 4 pages, 2011.
[20] A. B. Stern, H. D. Stewart, H. K. Singh, and A. V. Kshirsagar, "Pink urine after propofol anesthesia," Kidney International, vol. 78, no. 11, p. 1193, 2010.

[21] S. Urushidani and A. Kuriyama, "Green urine," QJM: An International Journal of Medicine, vol. 108, no. 8, Article ID hcv030, p. 675, 2015.

[22] E. Verhoeven, A. Capron, and P. Hantson, "Pink urine," Clinical Toxicology, vol. 52, no. 9, pp. 980-981, 2014.

[23] A. Krajčová, P. Waldauf, M. Anděl, and F. Duška, "Propofol infusion syndrome: a structured review of experimental studies and 153 published case reports," Critical Care, vol. 19, no. 1, article 398, 2015.

[24] M. B. Gatch and M. J. Forster, "Behavioral and toxicological effects of propofol," Behavioural Pharmacology, vol. 22, no. 7, pp. 718-722, 2011.

[25] R. J. Levy, "Clinical effects and lethal and forensic aspects of propofol," Journal of Forensic Sciences, vol. 56, no. 1, pp. S142S147, 2011.

[26] R. G. Ilic, "Fospropofol and remimazolam," International Anesthesiology Clinics, vol. 53, no. 2, pp. 76-90, 2015.

[27] G. M. Bengalorkar, K. Bhuvana, N. Sarala, and T. N. Kumar, "Fospropofol: clinical pharmacology," Journal of Anaesthesiology Clinical Pharmacology, vol. 27, no. 1, pp. 79-83, 2011.

[28] T. J. Gan, "Pharmacokinetic and pharmacodynamic characteristics of medications used for moderate sedation," Clinical Pharmacokinetics, vol. 45, no. 9, pp. 855-869, 2006.

[29] R. Boules, A. Szkiladz, and A. Nogid, "Fospropofol disodium (lusedra) injection for anesthesia-care sedation: a clinical review," P and T, vol. 37, no. 7, pp. 395-422, 2012.

[30] R. Lingamaneni, M. L. Birch, and H. C. Hemmings Jr., "Widespread inhibition of sodium channel-dependent glutamate release from isolated nerve terminals by isoflurane and propofol," Anesthesiology, vol. 95, no. 6, pp. 1460-1466, 2001.

[31] R. W. Olsen and G.-D. Li, "GABA(A) receptors as molecular targets of general anesthetics: identification of binding sites provides clues to allosteric modulation," Canadian Journal of Anesthesia, vol. 58, no. 2, pp. 206-215, 2011.

[32] S.-W. Ying and P. A. Goldstein, "Propofol suppresses synaptic responsiveness of somatosensory relay neurons to excitatory input by potentiating GABAA receptor chloride channels," Molecular Pain, vol. 1, no. 2, 2005.

[33] G. Trapani, A. Latrofa, M. Franco et al., "Propofol analogues. Synthesis, relationships between structure and affinity at $\mathrm{GABA}(\mathrm{A})$ receptor in rat brain, and differential electrophysiological profile at recombinant human GABA(A) receptors," Journal of Medicinal Chemistry, vol. 41, no. 11, pp. 1846-1854, 1998.

[34] K. D. Murugaiah and H. C. Hemmings Jr., "Effects of intravenous general anesthetics on $[3 \mathrm{H}] \mathrm{GABA}$ release from rat cortical synaptosomes," Anesthesiology, vol. 89, no. 4, pp. 919928, 1998.

[35] R. J. Dinis-Oliveira, "Metabolic profile of flunitrazepam: clinical and forensic toxicological aspects," Drug Metabolism Letters, vol. 11, no. 1, pp. 14-20, 2017.

[36] R. J. Dinis-Oliveira, "Metabolic profile of oxazepam and related benzodiazepines: clinical and forensic aspects," Drug Metabolism Reviews, pp. 1-13, 2017.

[37] H. P. Rang, J. M. Ritter, R. J. Flower, and G. Henderson, Rang and Dale's Pharmacology, Churchill Livingstone, 8th edition, 2016.

[38] N. P. Franks, "General anaesthesia: from molecular targets to neuronal pathways of sleep and arousal," Nature Reviews Neuroscience, vol. 9, no. 5, pp. 370-386, 2008. 
[39] T. Kushikata, K. Hirota, H. Yoshida, T. Kubota, H. Ishihara, and A. Matsuki, "Alpha-2 adrenoceptor activity affects propofolinduced sleep time," Anesthesia \& Analgesia, vol. 94, no. 5, pp. 1201-1206, 2002.

[40] L. L. Asserhoj, H. Mosbech, M. Kroigaard, and L. H. Garvey, "No evidence for contraindications to the use of propofol in adults allergic to egg, soy or peanutdagger," British Journal of Anaesthesia, vol. 116, no. 1, pp. 77-82, 2016.

[41] B. Bachmann-Mennenga, A. Ohlmer, and M. Heesen, "Incidence of pain after intravenous injection of a medium-/longchain triglyceride emulsion of propofol: an observational study in 1375 patients," Drug Research, vol. 53, no. 9, pp. 621-626, 2003.

[42] B. Bachmann-Mennenga, A. Ohlmer, R. H. Boedeker, M. Mann, B. Mühlenbruch, and M. Heesen, "Preventing pain during injection of propofol: effects of a new emulsion with lidocaine addition," European Journal of Anaesthesiology, vol. 24, no. 1, pp. 33-38, 2007.

[43] I. Wachowski, D. T. Jolly, J. Hrazdil, J. C. Galbraith, M. Greacen, and A. S. Clanachan, "The growth of microorganisms in propofol and mixtures of propofol and lidocaine," Anesthesia \& Analgesia, vol. 88, no. 1, pp. 209-212, 1999.

[44] M. T. Baker and M. Naguib, "Propofol: the challenges of formulation," Anesthesiology, vol. 103, no. 4, pp. 860-876, 2005.

[45] P. E. Marik, "Propofol: therapeutic indications and side-effects," Current Pharmaceutical Design, vol. 10, no. 29, pp. 3639-3649, 2004.

[46] A. A. Raoof, P. F. Augustijns, and R. K. Verbeeck, "In vivo assessment of intestinal, hepatic, and pulmonary first pass metabolism of propofol in the rat," Pharmaceutical Research, vol. 13, no. 6, pp. 891-895, 1996.

[47] R. Ceriana, A. Braschi, F. De Ponti, A. Crema, and D. De Amici, "Is rectal administration of propofol effective?" Anaesthesia, vol. 51, no. 5, p. 504, 1996.

[48] H. Hiraoka, K. Yamamoto, S. Miyoshi et al., "Kidneys contribute to the extrahepatic clearance of propofol in humans, but not lungs and brain," British Journal of Clinical Pharmacology, vol. 60, no. 2, pp. 176-182, 2005.

[49] H. Hiraoka, K. Yamamoto, N. Okano, T. Morita, F. Goto, and R. Horiuchi, "Changes in drug plasma concentrations of an extensively bound and highly extracted drug, propofol, in response to altered plasma binding," Clinical Pharmacology \& Therapeutics, vol. 75, no. 4, pp. 324-330, 2004.

[50] T. G. Short, J. A. Hannam, S. Laurent et al., "Refining targetcontrolled infusion: an assessment of pharmacodynamic targetcontrolled infusion of propofol and remifentanil using a response surface model of their combined effects on bispectral index," Anesthesia \& Analgesia, vol. 122, no. 1, pp. 90-97, 2016.

[51] J. Schuttler, H. Stoeckel, and H. Schwilden, "Pharmacokinetic and pharmacodynamic modelling of propofol ('Diprivan') in volunteers and surgical patients," Postgraduate Medical Journal, vol. 61, no. 3, pp. 53-54, 1985.

[52] P. H. Tonner, D. M. Poppers, and K. W. Miller, "The general anesthetic potency of propofol and its dependence on hydrostatic pressure," Anesthesiology, vol. 77, no. 5, pp. 926-931, 1992.

[53] J. L. Costela, R. Jiménez, R. Calvo, E. Suárez, and R. Carlos, "Serum protein binding of propofol in patients with renal failure or hepatic cirrhosis," Acta Anaesthesiologica Scandinavica, vol. 40, no. 6, pp. 741-745, 1996.

[54] A. L. Dawidowicz, R. Kalitynski, and A. Fijalkowska, "Free and bound propofol concentrations in human cerebrospinal fluid," British Journal of Clinical Pharmacology, vol. 56, no. 5, pp. 545550, 2003.
[55] J. X. Mazoit and K. Samii, "Binding of propofol to blood components: implications for pharmacokinetics and for pharmacodynamics," British Journal of Clinical Pharmacology, vol. 47, no. 1, pp. 35-42, 1999.

[56] E. Suarez, R. Calvo, M. K. Zamacona, and J. Lukas, "Binding of propofol to blood components," British Journal of Clinical Pharmacology, vol. 49, no. 4, pp. 380-381, 2000.

[57] I. D. Cockshott, E. J. Douglas, G. F. Plummer, and P. J. Simons, "The pharmacokinetics of propofol in laboratory animals," Xenobiotica, vol. 22, no. 3, pp. 369-375, 1992.

[58] P. Altmayer, U. Buch, and H. P. Buch, "Propofol binding to human blood proteins," Drug Research, vol. 45, no. 10, pp. 10531056, 1995.

[59] K. Allegaert, J. Vancraeynest, M. Rayyan et al., "Urinary propofol metabolites in early life after single intravenous bolus," British Journal of Anaesthesia, vol. 101, no. 6, pp. 827-831, 2008.

[60] A. A. Raoof, L. J. Van Obbergh, J. De Ville De Goyet, and R. K. Verbeeck, "Extrahepatic glucuronidation of propofol in man: possible contribution of gut wall and kidney," European Journal of Clinical Pharmacology, vol. 50, no. 1-2, pp. 91-96, 1996.

[61] S.-H. Zhang, Q. Li, S.-L. Yao, and B.-X. Zeng, "Subcellular expression of UGT1A6 and CYP1A1 responsible for propofol metabolism in human brain," Acta Pharmacologica Sinica, vol. 22, no. 11, pp. 1013-1017, 2001.

[62] P. Veroli, B. O’kelly, F. Bertrand, J. H. Trouvin, R. Farinotti, and C. Ecoffey, "Extrahepatic metabolism of propofol in man during the anhepatic phase of orthotopic liver transplantation," British Journal of Anaesthesia, vol. 68, no. 2, pp. 183-186, 1992.

[63] P. A. Gray, G. R. Park, I. D. Cockshott, E. J. Douglas, B. Shuker, and P. J. Simons, "Propofol metabolism in man during the anhepatic and reperfusion phases of liver transplantation," Xenobiotica, vol. 22, no. 1, pp. 105-114, 1992.

[64] J. Y. Khokhar and R. F. Tyndale, "Drug metabolism within the brain changes drug response: Selective manipulation of brain CYP2B alters propofol effects," Neuropsychopharmacology, vol. 36, no. 3, pp. 692-700, 2011.

[65] D. Takizawa, H. Hiraoka, F. Goto, K. Yamamoto, and R. Horiuchi, "Human kidneys play an important role in the elimination of propofol," Anesthesiology, vol. 102, no. 2, pp. 327-330, 2005.

[66] J. A. Kuipers, F. Boer, W. Olieman, A. G. L. Burm, and J. G. Bovill, "First-pass lung uptake and pulmonary clearance of propofol: assessment with a recirculatory indocyanine green pharmacokinetic model," Anesthesiology, vol. 91, no. 6, pp. 17801787, 1999.

[67] A. L. Dawidowicz, E. Fornal, M. Mardarowicz, and A. Fijalkowska, "The role of human lungs in the biotransformation of propofol," Anesthesiology, vol. 93, no. 4, pp. 992-997, 2000.

[68] P. J. Simons, I. D. Cockshott, E. J. Douglas, E. A. Gordon, S. Knott, and R. J. Ruane, "Species differences in blood profiles, metabolism and excretion of 14c-propofol after intravenous dosing to rat, dog and rabbit," Xenobiotica, vol. 21, no. 10, pp. 1243-1256, 1991.

[69] P. J. Simons, I. D. Cockshott, E. J. Douglas, E. A. Gordon, S. Knott, and R. J. Ruane, "Distribution in female rats of an anaesthetic intravenous dose of 14c-propofol," Xenobiotica, vol. 21, no. 10, pp. 1325-1335, 1991.

[70] J. Guitton, M. Desage, A. Lepape, C. S. Degoute, M. Manchon, and J. L. Brazier, "Quantitation of propofol in whole blood by gas chromatography-mass spectrometry," Journal of Chromatography B: Biomedical Sciences and Applications, vol. 669, no. 2, pp. 358-365, 1995. 
[71] P. J. Simons, I. D. Cockshott, J. B. Glen, E. A. Gordon, S. Knott, and R. J. Ruane, "Disposition and pharmacology of propofol glucuronide administered intravenously to animals," Xenobiotica, vol. 22, no. 11, pp. 1267-1273, 1992.

[72] M. Saeki, Y. Saito, H. Jinno et al., "Three novel single nucleotide polymorphisms in UGT1A9," Drug Metabolism and Pharmacokinetics, vol. 18, no. 2, pp. 146-149, 2003.

[73] K. A. B. Findlay, E. Kaptein, T. J. Visser, and B. Burchell, "Characterization of the uridine diphosphate-glucuronosyltransferase-catalyzing thyroid hormone glucuronidation in man," The Journal of Clinical Endocrinology \& Metabolism, vol. 85, no. 8, pp. 2879-2883, 2000.

[74] J.-F. Gagne, V. Montminy, P. Belanger, K. Journault, G. Gaucher, and C. Guillemette, "Common human UGT1A polymorphisms and the altered metabolism of irinotecan active metabolite 7ethyl-10-hydroxycamptothecin (SN-38)," Molecular Pharmacology, vol. 62, no. 3, pp. 608-617, 2002.

[75] C. Bleeker, T. Vree, A. Lagerwerf, and E. Willems-Van Bree, "Recovery and long-term renal excretion of propofol, its glucuronide, and two di-isopropylquinol glucuronides after propofol infusion during surgery," British Journal of Anaesthesia, vol. 101, no. 2, pp. 207-212, 2008.

[76] T. B. Vree, A. J. Lagerwerf, C. P. Bleeker, and P. M. R. M. de Grood, "Direct high-performance liquid chromatography determination of propofol and its metabolite quinol with their glucuronide conjugates and preliminary pharmacokinetics in plasma and urine of man," Journal of Chromatography B: Biomedical Sciences and Applications, vol. 721, no. 2, pp. 217-228, 1999.

[77] C. P. Strassburg, M. P. Manns, and R. H. Tukey, "Expression of the UDP-glucuronosyltransferase 1A locus in human colon. Identification and characterization of the novel extrahepatic UGT1A8," The Journal of Biological Chemistry, vol. 273, no. 15, pp. 8719-8726, 1998.

[78] C. Albert, M. Vallee, G. Beaudry, A. Bélanger, and D. W. Hum, "The monkey and human uridine diphosphateglucuronosyltransferase UGT1A9, expressed in steroid target tissues, are estrogen-conjugating enzymes," Endocrinology, vol. 140, no. 7, pp. 3292-3302, 1999.

[79] R. K. Mehlotra, M. J. Bockarie, and P. A. Zimmerman, "Prevalence of UGT1A9 and UGT2B7 nonsynonymous single nucleotide polymorphisms in West African, Papua New Guinean, and North American populations," European Journal of Clinical Pharmacology, vol. 63, no. 1, pp. 1-8, 2007.

[80] E. Choong, I. Loryan, M. Lindqvist et al., "Sex difference in formation of propofol metabolites: a replication study," Basic and Clinical Pharmacology and Toxicology, vol. 113, no. 2, pp. 126-131, 2013.

[81] M. S. Khan, E.-L. Zetterlund, H. Gréen et al., "Pharmacogenetics, plasma concentrations, clinical signs and eeg during propofol treatment," Basic and Clinical Pharmacology and Toxicology, vol. 115, no. 6, pp. 565-570, 2014.

[82] G. Iohom, M. Ni Chonghaile, J. K. O’Brien, A. J. Cunningham, D. F. Fitzgerald, and D. C. Shields, "An investigation of potential genetic determinants of propofol requirements and recovery from anaesthesia," European Journal of Anaesthesiology, vol. 24, no. 11, pp. 912-919, 2007.

[83] J. Gu, K. Lu, P. Xia et al., "Pharmacokinetics of propofol and extrahepatic ugtla6 gene expression in anhepatic rats," Pharmacology, vol. 84, no. 4, pp. 219-226, 2009.

[84] B. T. Ethell, K. Beaumont, D. J. Rance, and B. Burchell, "Use of cloned and expressed human UDP-glucuronosyltransferases for the assessment of human drug conjugation and identification of potential drug interactions," Drug Metabolism and Disposition, vol. 29, no. 1, pp. 48-53, 2001.

[85] M. K. Shelby, N. J. Cherrington, N. R. Vansell, and C. D. Klaassen, "Tissue mRNA expression of the rat UDPglucuronosyltransferase gene family," Drug Metabolism and Disposition, vol. 31, no. 3, pp. 326-333, 2003.

[86] B. T. Ethell, S. Ekins, J. Wang, and B. Burchell, "Quantitative structure activity relationships for the glucuronidation of simple phenols by expressed human UGT1A6 and UGT1A9," Drug Metabolism and Disposition, vol. 30, no. 6, pp. 734-738, 2002.

[87] Z. Cheng, A. Radominska-Pandya, and T. R. Tephly, "Studies on the substrate specificity of human intestinal UDP- lucuronosyltransferases 1A8 and 1A10," Drug Metabolism and Disposition: The Biological Fate of Chemicals, vol. 27, no. 10, pp. 1165-1170, 1999.

[88] T. K. Kiang, M. H. Ensom, and T. K. Chang, "UDPglucuronosyltransferases and clinical drug-drug interactions," Pharmacology and Therapeutics, vol. 106, no. 1, pp. 97-132, 2005.

[89] M. H. Court, "Isoform-selective probe substrates for in vitro studies of human UDP-glucuronosyltransferases," Methods in Enzymology, vol. 400, article no. 7, pp. 104-116, 2005.

[90] M. Mukai, T. Isobe, K. Okada, M. Murata, M. Shigeyama, and N. Hanioka, "Species and sex differences in propofol glucuronidation in liver microsomes of humans, monkeys, rats and mice," Die Pharmazie, vol. 70, no. 7, pp. 466-470, 2015.

[91] T. B. Vree, A. M. Baars, and P. M. R. M. De Grood, "Highperformance liquid chromatographic determination and preliminary pharmacokinetics of propofol and its metabolites in human plasma and urine," Journal of Chromatography B: Biomedical Sciences and Applications, vol. 417, no. 2, pp. 458464, 1987.

[92] S. Cohen, F. Lhuillier, Y. Mouloua, B. Vignal, P. Favetta, and J. Guitton, "Quantitative measurement of propofol and in main glucuroconjugate metabolites in human plasma using solid phase extraction-liquid chromatography-tandem mass spectrometry," Journal of Chromatography B, vol. 854, no. 1-2, pp. 165-172, 2007.

[93] A. Maas, C. Maier, B. Michel-Lauter, S. Broecker, B. Madea, and C. Hess, "Verification of propofol sulfate as a further human propofol metabolite using LC-ESI-QQQ-MS and LCESI-QTOF-MS analysis," Drug Metabolism and Personalized Therapy, vol. 32, no. 1, pp. 67-72, 2017.

[94] P. K. Janicki, M. F. M. James, and W. A. R. Erskine, "Propofol inhibits enzymatic degradation of alfentanil and sufentanil by isolated liver microsomes in vitro," British Journal of Anaesthesia, vol. 68, no. 3, pp. 311-312, 1992.

[95] J. Guitton, T. Buronfosse, M. Desage et al., "Possible involvement of multiple human cytochrome $\mathrm{P} 450$ isoforms in the liver metabolism of propofol," British Journal of Anaesthesia, vol. 80, no. 6, pp. 788-795, 1998.

[96] J. G. Restrepo, E. Garcia-Martín, C. Martínez, and J. A. G. Agúndez, "Polymorphic drug metabolism in anaesthesia," Current Drug Metabolism, vol. 10, no. 3, pp. 236-246, 2009.

[97] A. Mikstacki, O. Zakerska-Banaszak, M. Skrzypczak-Zielinska et al., "The effect of UGT1A9, CYP2B6 and CYP2C9 genes polymorphism on individual differences in propofol pharmacokinetics among Polish patients undergoing general anaesthesia," Journal of Applied Genetics, vol. 58, no. 2, pp. 213-220, 2017. 
[98] U. M. Zanger and K. Klein, "Pharmacogenetics of cytochrome P450 2B6 (CYP2B6): advances on polymorphisms, mechanisms, and clinical relevance," Frontiers in Genetics, vol. 4, article 24, 2013.

[99] R. J. Dinis-Oliveira, "Metabolomics of methadone: clinical and forensic toxicological implications and variability of dose response," Drug Metabolism Reviews, vol. 48, no. 4, pp. 568-576, 2016.

[100] Y. Oda, N. Hamaoka, T. Hiroi et al., "Involvement of human liver cytochrome P4502B6 in the metabolism of propofol," British Journal of Clinical Pharmacology, vol. 51, no. 3, pp. 281-285, 2001.

[101] L. M. Hesse, K. Venkatakrishnan, M. H. Court et al., "CYP2B6 mediates the in vitro hydroxylation of bupropion: potential drug interactions with other antidepressants," Drug Metabolism and Disposition, vol. 28, no. 10, pp. 1176-1183, 2000.

[102] O. Mastrogianni, E. Gbandi, A. Orphanidis et al., "Association of the CYP2B6 c.516G $>\mathrm{T}$ polymorphism with high blood propofol concentrations in women from Northern Greece," Drug Metabolism and Pharmacokinetics, vol. 29, no. 2, pp. 215218, 2014.

[103] P. Favetta, C. Dufresne, M. Desage et al., "Detection of new propofol metabolites in human urine using gas chromatography/mass spectrometry and liquid chromatography/mass spectrometry techniques," Rapid Communications in Mass Spectrometry, vol. 14, no. 20, pp. 1932-1936, 2000.

[104] M. T. Baker, M. V. Chadam, and W. C. Ronnenberg Jr., "Inhibitory effects of propofol on cytochrome P450 activities in rat hepatic microsomes," Anesthesia \& Analgesia, vol. 76, no. 4, pp. 817-821, 1993.

[105] T. L. Chen, T. H. Ueng, S. H. Chen, P. H. Lee, S. Z. Fan, and C. C. Liu, "Human cytochrome P450 mono-oxygenase system is suppressed by propofol," British Journal of Anaesthesia, vol. 74, no. 5, pp. 558-562, 1995.

[106] B. J. Lichtenbelt, E. Olofsen, A. Dahan, J. W. Van Kleef, M. M. Struys, and J. Vuyk, "Propofol reduces the distribution and clearance of midazolam," Anesthesia \& Analgesia, vol. 110, no. 6, pp. 1597-1606, 2010.

[107] Y. Mano, T. Usui, and H. Kamimura, "Substrate-dependent modulation of UDP-glucuronosyltransferase 1A1 (UGT1A1) by propofol in recombinant human UGT1A1 and human liver microsomes," Basic \& Clinical Pharmacology \& Toxicology, vol. 101, no. 3, pp. 211-214, 2007.

[108] P. Favetta, C.-S. Degoute, J.-P. Perdrix, C. Dufresne, R. Boulieu, and J. Guitton, "Propofol metabolites in man following propofol induction and maintenance," British Journal of Anaesthesia, vol. 88, no. 5, pp. 653-658, 2002.

[109] P. J. Simons, I. D. Cockshott, E. J. Douglas, E. A. Gordon, K. Hopkins, and M. Rowland, "Disposition in male volunteers of a subanaesthetic intravenous dose of an oil in water emulsion of 14C-propofol," Xenobiotica, vol. 18, no. 4, pp. 429-440, 1988.

[110] T. B. Vree, P.-M. R. M. De Grood, H. B. H. Van Beem, and L. H. D. J. Booij, "Disposition and renal clearance of propofol and its glucuronide metabolites after a short intravenous infusion of propofol," Clinical Drug Investigation, vol. 13, no. 3, pp. 145-151, 1997.

[111] T. L. Chen, H. J. Wang, C. H. Huang, C. C. Liu, and T. H. Ueng, "Difference between in vivo and in vitro effects of propofol on defluorination and metabolic activities of hamster hepatic cytochrome P450-dependent mono-oxygenases," British Journal of Anaesthesia, vol. 75, no. 4, pp. 462-466, 1995.
[112] E. Gepts, F. Camu, I. D. Cockshott, and E. J. Douglas, "Disposition of propofol administered as constant rate intravenous infusions in humans," Anesthesia \& Analgesia, vol. 66, no. 12, pp. 1256-1263, 1987.

[113] I. Matot, C. F. Neely, R. Y. Katz, and G. R. Neufeld, "Pulmonary uptake of propofol in cats: effect of fentanyl and halothane," Anesthesiology, vol. 78, no. 6, pp. 1157-1165, 1993.

[114] B. Mahajan, S. Kaushal, and R. Mahajan, “Fospropofol," Journal of Pharmacology and Pharmacotherapeutics, vol. 3, no. 3, pp. 293-296, 2012.

[115] J. Fechner, H. Ihmsen, C. Jeleazcov, and J. Schüttler, "Fospropofol disodium, a water-soluble prodrug of the intravenous anesthetic propofol (2,6-diisopropylphenol)," Expert Opinion on Investigational Drugs, vol. 18, no. 10, pp. 1565-1571, 2009.

[116] M. K. Martinasevic, M. D. Green, J. Baron, and T. R. Tephly, "Folate and 10-formyltetrahydrofolate dehydrogenase in human and rat retina: relation to methanol toxicity," Toxicology and Applied Pharmacology, vol. 141, no. 2, pp. 373-381, 1996.

[117] J. Fechner, H. Schwilden, and J. Schüttler, "Pharmacokinetics and pharmacodynamics of GPI 15715 or fospropofol (Aquavan Injection) - A water-soluble propofol prodrug," Handbook of Experimental Pharmacology, vol. 182, pp. 253-266, 2008.

[118] M. Welliver and S. M. Rugari, "New drug, fospropofol disodium: a propofol prodrug," AANA Journal, vol. 77, no. 4, pp. 301-308, 2009.

[119] A. d'Alessandro, J. D. Osterloh, P. Chuwers, P. J. Quinlan, T. J. Kelly, and C. E. Becker, "Formate in serum and urine after controlled methanol exposure at the threshold limit value," Environmental Health Perspectives, vol. 102, no. 2, pp. 178-181, 1994.

[120] H. R. Wallage and J. H. Watterson, "Formic acid and methanol concentrations in death investigations," Journal of Analytical Toxicology, vol. 32, no. 3, pp. 241-247, 2008.

[121] K. M. Wozniak, J. J. Vornov, B. M. Mistry, Y. Wu, R. Rais, and B. S. Slusher, "Gastrointestinal delivery of propofol from fospropofol: its bioavailability and activity in rodents and human volunteers," Journal of Translational Medicine, vol. 13, no. 1, article no. 170, 2015.

[122] K. P. Garnock-Jones and L. J. Scott, "Fospropofol," Drugs, vol. 70, no. 4, pp. 469-477, 2010.

[123] G. Rawal and S. Yadav, "Green urine due to propofol: a case report with review of literature," Journal of Clinical and Diagnostic Research, vol. 9, no. 11, pp. OD03-OD04, 2015.

[124] D. Gupta and R. Gupta, "Green urine," The Scientific World Journal, vol. 11, pp. 1101-1102, 2011.

[125] J. van Rosmalen and J. A. van Oers, "A young man with green urine," Nederlands Tijdschrift Voor Geneeskunde, vol. 160, no. 0, p. D585, 2016.

[126] J.-S. Lee, H.-S. Jang, and B.-J. Park, "Green discoloration of urine after propofol infusion," Korean Journal of Anesthesiology, vol. 65, no. 2, pp. 177-179, 2013.

[127] D. W. Barbara and F. X. Whalen Jr., "Propofol induction resulting in green urine discoloration," Anesthesiology, vol. 116, no. 4, p. 924, 2012.

[128] S. A. Blakey and J. A. Hixson-Wallace, "Clinical significance of rare and benign side effects: propofol and green urine," Pharmacotherapy, vol. 20, no. 9 I, pp. 1120-1122, 2000.

[129] A. Masuda, K. Hirota, T. Satone, and Y. Ito, "Pink urine during propofol anesthesia," Anesthesia and Analgesia, vol. 83, no. 3, pp. 666-667, 1996. 
[130] J. Nates, A. Avidan, Y. Gozal, and M. Gertel, "Appearance of white urine during propofol anesthesia," Anesthesia and Analgesia, vol. 81, no. 1, p. 210, 1995.

[131] M. J. Gillett and J. R. Burnett, "Medications and green urine," Internal Medicine Journal, vol. 36, no. 1, pp. 64-66, 2006.

[132] G. Carpenito and I. Kurtz, "Green urine in a critically ill patient," American Journal of Kidney Diseases, vol. 39, no. 4, p. E20, 2002.

[133] F. Ehrig, S. Waller, M. Misra, and Z. J. Twardowski, "A case of 'green urine"' Nephrology Dialysis Transplantation, vol. 14, no. 1, pp. 190-192, 1999.

[134] F. Pak, "Green urine: an association with metoclopramide," Nephrology Dialysis Transplantation, vol. 19, no. 10, pp. 26772677, 2004.

[135] K. A. Tønseth, T. T. Tindholdt, B. M. Hokland, and F. E. Åbyholm, "Green urine after surgical treatment of pressure ulcer," Journal of Plastic Surgery and Hand Surgery, vol. 41, no. 1, pp. 39-41, 2007.

[136] J. Lepenies, E. Toubekis, U. Frei, and R. Schindler, "Green urine after motorcycle accident," Nephrology Dialysis Transplantation , vol. 15, no. 5, pp. 725-726, 2000.

[137] A. B. Pedersen, T. K. Kobborg, and J. R. Larsen, "Grassgreen urine from propofol infusion," Acta Anaesthesiologica Scandinavica, vol. 59, no. 2, pp. 265-267, 2015.

[138] N. Kato and R. Ogawa, "Does use of propofol in heavy alcohol drinkers tend to discolor their urine?" Acta Anaesthesiologica Scandinavica, vol. 43, no. 8, pp. 868-869, 1999.

[139] B. D. Ku, K. C. Park, and S. S. Yoon, "Dark green discoloration of the urine after prolonged propofol infusion: a case report," Journal of Clinical Pharmacy and Therapeutics, vol. 36, no. 6, pp. 734-736, 2011.

[140] K. Fujii-Abe, H. Kawahara, and H. Fukayama, "An analysis of green discoloration of urine caused by propofol infusion," Journal of Clinical Anesthesia, vol. 35, pp. 358-360, 2016.

[141] C. C. Callander, J. S. Thomas, and C. J. Evans, "Propofol and the colour green," Anaesthesia, vol. 44, no. 1, p. 82, 1989.

[142] J. Motsch, H. Schmidt, A. Bach, B. W. Bottiger, and H. Bohrer, "Long-term sedation with propofol and green discolouration of the liver," European Journal of Anaesthesiology, vol. 11, no. 6, pp. 499-502, 1994.

[143] L. Potton, A. Bonadona, C. Minet, and J. F. Timsit, "Pink urine," Intensive Care Medicine, vol. 39, no. 3, pp. 389-390, 2013.

[144] A. Masuda, T. Asahi, M. Sakamaki, K. Nakamaru, K. Hirota, and Y. Ito, "Uric acid excretion increases during propofol anesthesia," Anesthesia \& Analgesia, vol. 85, no. 1, pp. 144-148, 1997.

[145] K. Okubo, H. Okubo, Y. Kamijo, and M. Higuchi, "Pink urine syndrome," Internal Medicine, vol. 50, no. 18, p. 2057, 2011.

[146] M. Deitel, D. A. Thompson, C. F. Saldanha, P. J. Ramshaw, M. C. Patterson, and K. P. Pritzker, "'Pink urine' in morbidly obese patients following gastric partitioning," Canadian Medical Association Journal, vol. 130, no. 8, pp. 1007-1011, 1984.

[147] R. Saran, S. Abdullah, S. Goel, K. D. Nolph, and B. E. Terry, "An unusual cause of pink urine," Nephrology Dialysis Transplantation, vol. 13, no. 6, pp. 1579-1580, 1998.

[148] M. Slawson, "Thirty-three drugs that discolor urine and/or stools," $R N$, vol. 43, no. 1, pp. 40-41, 1980.

[149] D. S. Wishart, T. Jewison, A. C. Guo et al., "HMDB 3.0-the human metabolome database in 2013," Nucleic Acids Research, vol. 41, no. 1, pp. D801-D807, 2013.
[150] V. Ghini, F. T. Unger, L. Tenori, P. Turano, H. Juhl, and K. A. David, "Metabolomics profiling of pre-and post-anesthesia plasma samples of colorectal patients obtained via Ficoll separation," Metabolomics, vol. 11, no. 6, pp. 1769-1778, 2015.

[151] Z. Jacob, H. Li, R. Makaryus et al., "Metabolomic profiling of children's brains undergoing general anesthesia with sevoflurane and propofol," Anesthesiology, vol. 117, no. 5, pp. 1062-1071, 2012.

[152] R. Makaryus, H. Lee, M. Yu et al., "The metabolomic profile during isoflurane anesthesia differs from propofol anesthesia in the live rodent brain," Journal of Cerebral Blood Flow \& Metabolism, vol. 31, no. 6, pp. 1432-1442, 2011.

[153] M. T. Alkire, R. J. Haier, S. J. Barker, N. K. Shah, J. C. Wu, and Y. J. Kao, "Cerebral metabolism during propofol anesthesia in humans studied with positron emission tomography," Anesthesiology, vol. 82, no. 2, pp. 393-403, 1995.

[154] O. H. Drummer, "A fatality due to propofol poisoning," Journal of Forensic Sciences, vol. 37, no. 4, pp. 1186-1189, 1992.

[155] J. W. Follette and W. J. Farley, "Anesthesiologist addicted to propofol," Anesthesiology, vol. 77, no. 4, pp. 817-818, 1992.

[156] J. H. Diaz and A. D. Kaye, "Death by Propofol," The Journal of the Louisiana State Medical Society, vol. 169, no. 2, pp. 28-32, 2017.

[157] A. Maas, C. Maier, S. Iwersen-Bergmann, B. Madea, and C. Hess, "Simultaneous extraction of propofol and propofol glucuronide from hair followed by validated LC-MS/MS analyses," Journal of Pharmaceutical and Biomedical Analysis, vol. 146, pp. 236-243, 2017.

[158] R. R. Kirby, J. M. Colaw, and M. M. Douglas, "Death from propofol: accident, suicide, or murder?" Anesthesia and Analgesia, vol. 108, no. 4, pp. 1182-1184, 2009.

[159] G. Klausz, K. Róna, I. Kristóf, and K. Töro, "Evaluation of a fatal propofol intoxication due to self administration," Journal of Forensic and Legal Medicine, vol. 16, no. 5, pp. 287-289, 2009.

[160] A. Roussin, M. Mirepoix, G. Lassabe et al., "Death related to a recreational abuse of propofol at therapeutic dose range," British Journal of Anaesthesia, vol. 97, no. 2, p. 268, 2006.

[161] B. Wu, W. Lin, H. Wang et al., "Glucocorticoid receptor in rat nucleus accumbens: its roles in propofol addictions," Neuroscience Letters, vol. 662, pp. 115-121, 2018.

[162] B. Wang, X. Yang, A. Sun et al., "Extracellular signalregulated kinase in nucleus accumbens mediates propofol selfadministration in rats," Neuroscience Bulletin, vol. 32, no. 6, pp. 531-537, 2016.

[163] A. Roussin, J.-L. Montastruc, and M. Lapeyre-Mestre, "Pharmacological and clinical evidences on the potential for abuse and dependence of propofol: a review of the literature," Fundamental \& Clinical Pharmacology, vol. 21, no. 5, pp. 459-466, 2007.

[164] B. Wu, Y. Liang, Z. Dong et al., "Glucocorticoid receptor mediated the propofol self-administration by dopamine D1 receptor in nucleus accumbens," Neuroscience, vol. 328, pp. 184193, 2016.

[165] M. Soyka and C. G. Schutz, "Propofol dependency," Addiction, vol. 92, no. 10, pp. 1369-1370, 1997.

[166] J. Au, W. S. Walker, and D. H. T. Scott, "Withdrawal syndrome after propofol infusion," Anaesthesia, vol. 45, no. 9, pp. 741-742, 1990.

[167] U. Bonnet and N. Scherbaum, "Craving dominates propofol addiction of an affected physician," Journal of Psychoactive Drugs, vol. 44, no. 2, pp. 186-190, 2012. 
[168] E. Trampitsch, M. Oher, I. Pointner, R. Likar, R. Jost, and H. V. Schalk, "Propofol infusion syndrome," Der Anaesthesist, vol. 55, no. 11, pp. 1166-1168, 2006.

[169] P. C. A. Kam and D. Cardone, "Propofol infusion syndrome," Anaesthesia, vol. 62, no. 7, pp. 690-701, 2007.

[170] M. M. Zaccheo and D. H. Bucher, "Propofol infusion syndrome: a rare complication with potentially fatal results," Critical Care Nurse, vol. 28, no. 3, pp. 18-27, 2008.

[171] A. Eziefule, S. Elshatanoufy, M. Thakur, and F. Rocha, "Propofol-related infusion syndrome in the peripartum period," American Journal of Perinatology Reports, vol. 6, no. 4, pp. e368e371, 2016.

[172] S. Iwersen-Bergmann, P. Rösner, H. C. Kühnau, M. Junge, and A. Schmoldt, "Death after excessive propofol abuse," International Journal of Legal Medicine, vol. 114, no. 4-5, pp. 248-251, 2001.

[173] E. F. Kranioti, A. Mavroforou, P. Mylonakis, and M. Michalodimitrakis, "Lethal self administration of propofol (Diprivan). a case report and review of the literature," Forensic Science International, vol. 167, no. 1, pp. 56-58, 2007.

[174] M. Schulz, S. Iwersen-Bergmann, H. Andresen, and A. Schmoldt, "Therapeutic and toxic blood concentrations of nearly 1,000 drugs and other xenobiotics," Critical Care, vol. 16, no. 4, article R136, 2012.

[175] T. C. Chao, D. S. T. Lo, P. P. S. Chui, and T. H. Koh, “The first fatal 2,6-di-isopropylphenol (propofol) poisoning in Singapore: a case report," Forensic Science International, vol. 66, no. 1, pp. $1-7,1994$.

[176] T. G. Short and P. T. Chui, "Propofol and midazolam act synergistically in combination," British Journal of Anaesthesia, vol. 67 , no. 5, pp. 539-545, 1991.

[177] T. Perl, E. Carstens, A. Hirn et al., "Determination of serum propofol concentrations by breath analysis using ion mobility spectrometry," British Journal of Anaesthesia, vol. 103, no. 6, pp. 822-827, 2009.

[178] J. Csomor, I. Murinova, K. Broulikova, O. Kucerka et al., "Propofol-induced acute pancreatitis," Journal of Clinical Pharmacy and Therapeutics, vol. 42, no. 4, pp. 495-498, 2017.

[179] J. W. Devlin, A. K. Lau, and M. A. Tanios, "Propofol-associated hypertriglyceridemia and pancreatitis in the intensive care unit: an analysis of frequency and risk factors," Pharmacotherapy, vol. 25, no. 10, pp. 1348-1352, 2005.

[180] T. M. Muniraj and H. R. A. Aslanian, "Hypertriglyceridemia independent propofol-induced pancreatitis," Journal of the Pancreas, vol. 13, no. 4, pp. 451-453, 2012.

[181] E. N. Aroke and J. R. Dungan, "Pharmacogenetics of anesthesia: an integrative review," Nursing Research, vol. 65, no. 4, pp. 318330, 2016.

[182] T. W. Schnider, C. F. Minto, P. L. Gambus et al., "The influence of method of administration and covariates on the pharmacokinetics of propofol in adult volunteers," Anesthesiology, vol. 88, no. 5, pp. 1170-1182, 1998.

[183] L. I. Cortinez, B. J. Anderson, A. Penna et al., "Influence of obesity on propofol pharmacokinetics: derivation of a pharmacokinetic model," British Journal of Anaesthesia, vol. 105, no. 4, pp. 448-456, 2010.

[184] F. F. Buchanan, P. S. Myles, and F. Cicuttini, "Effect of patient sex on general anaesthesia and recovery," British Journal of Anaesthesia, vol. 106, no. 6, pp. 832-839, 2011.

[185] A. Smits, P. Annaert, and K. Allegaert, "Biomarkers of propofol metabolism in neonates: the quest beyond ontogeny," Biomarkers in Medicine, vol. 11, no. 11, pp. 933-936, 2017.
[186] J. E. Richardson, P. S. Garcia, K. K. O’Toole, J. M. Derry, S. V. Bell, and A. Jenkins, "A conserved tyrosine in the beta2 subunit M4 segment is a determinant of gamma-aminobutyric acid type A receptor sensitivity to propofol," Anesthesiology, vol. 107, no. 3, pp. 412-418, 2007.

[187] M. D. Krasowski, K. Nishikawa, N. Nikolaeva, A. Lin, and N. L. Harrison, "Methionine 286 in transmembrane domain 3 of the GABAA receptor $\beta$ subunit controls a binding cavity for propofol and other alkylphenol general anesthetics," Neuropharmacology, vol. 41, no. 8, pp. 952-964, 2001.

[188] R. Jurd, M. Arras, S. Lambert et al., "General anesthetic actions in vivo strongly attenuated by a point mutation in the GABA(A) receptor beta3 subunit." The FASEB journal : official publication of the Federation of American Societies for Experimental Biology, vol. 17, no. 2, pp. 250-252, 2003.

[189] D. W. Lam and J. N. Reynolds, "Modulatory and direct effects of propofol on recombinant GABA(A) receptors expressed in Xenopus oocytes: Influence of $\alpha$ - and $\gamma 2$-subunits," Brain Research, vol. 784, no. 1-2, pp. 179-187, 1998. 

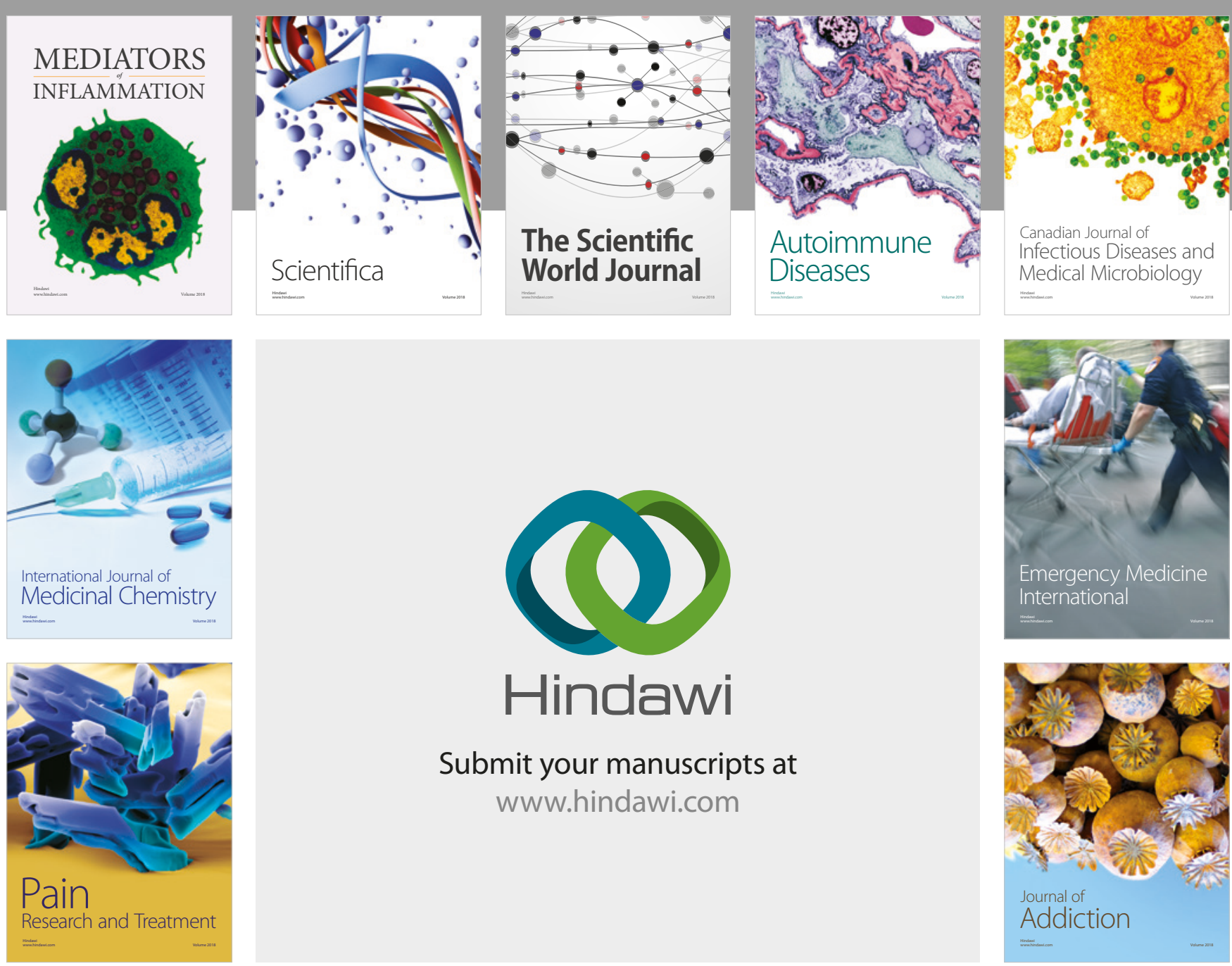

Canadian Journal of
Infectious Diseases and Medical Microbiology

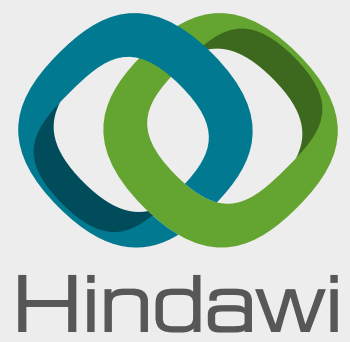

Submit your manuscripts at

www.hindawi.com
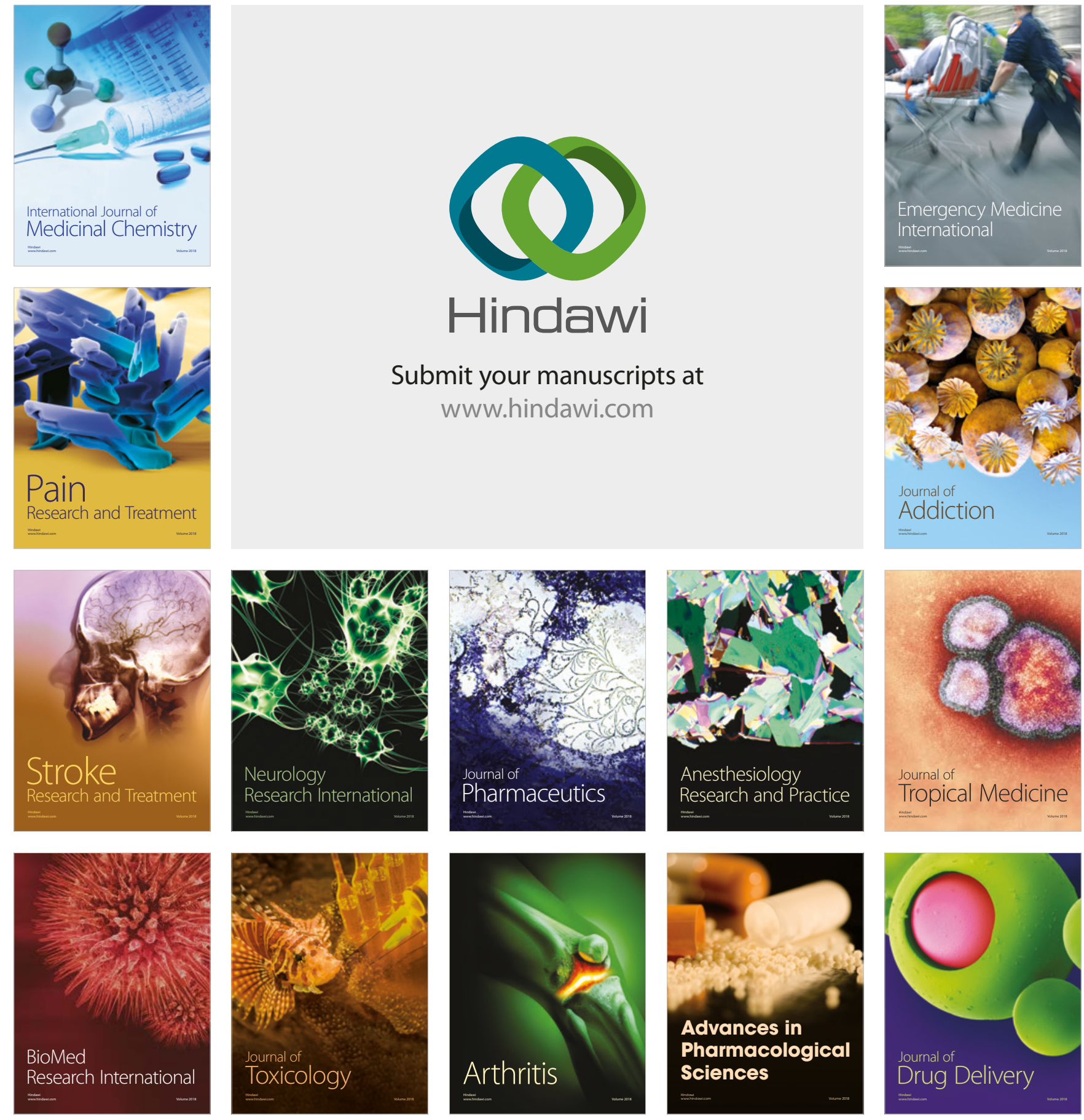